\title{
Wing Shape Sensing from Measured Strain
}

\author{
Chan-gi Pak ${ }^{1}$ \\ NASA Armstrong Flight Research Center, Edwards, CA 93523-0273
}

\begin{abstract}
A new two-step theory is investigated for predicting the deflection and slope of an entire structure using strain measurements at discrete locations. In the first step, a measured strain is fitted using a piecewise least-squares curve fitting method together with the cubic spline technique. These fitted strains are integrated twice to obtain deflection data along the fibers. In the second step, computed deflection along the fibers are combined with a finite element model of the structure in order to interpolate and extrapolate the deflection and slope of the entire structure through the use of the System Equivalent Reduction and Expansion Process. The theory is first validated on a computational model, a cantilevered rectangular plate wing. The theory is then applied to test data from a cantilevered swept-plate wing model. Computed results are compared with finite element results, results using another strainbased method, and photogrammetry data. For the computational model under an aeroelastic load, maximum deflection errors in the fore and aft, lateral, and vertical directions are $-3.2 \%, 0.28 \%$, and $0.09 \%$, respectively; and maximum slope errors in roll and pitch directions are $0.28 \%$ and $-3.2 \%$, respectively. For the experimental model, deflection results at the tip are shown to be accurate to within $3.8 \%$ of the photogrammetry data and are accurate to within $2.2 \%$ in most cases. In general, excellent matching between target and computed values are accomplished in this study. Future refinement of this theory will allow it to monitor the deflection and health of an entire aircraft in real time, allowing for aerodynamic load computation, active flexible motion control, and active induced drag reduction.
\end{abstract}

\section{Nomenclature}

$\begin{array}{ll}\text { AFRC } & =\text { Armstrong Flight Research Center } \\ \text { cp } & =\text { pressure coefficient } \\ c(s) & =\text { vertical distance from neutral axis to surface at s, inch } \\ \text { DOF } & =\text { degrees of freedom } \\ E & =\text { Young's modulus, Msi } \\ \text { FBG } & =\text { fiber Bragg grating } \\ \text { FE } & =\text { finite element } \\ \text { FOSS } & =\text { fiber optic strain sensing } \\ \text { NASA } & =\text { National Aeronautics and Space Administration } \\ \left\{\widetilde{\boldsymbol{q}}_{\boldsymbol{M}}\right\} & =\text { measured master degrees of freedom } \\ \{\boldsymbol{q}(\boldsymbol{t})\} & =\text { generalized displacement vector at time (t) } \\ \left\{\boldsymbol{q}_{\boldsymbol{M}}(\boldsymbol{t})\right\} & =\text { master degrees of freedom at time }(\mathrm{t}) \\ \left\{\boldsymbol{q}_{S}(\boldsymbol{t})\right\} & =\text { slave degrees of freedom at time }(\mathrm{t}) \\ \mathrm{SEREP} & =\text { System Equivalent Reduction Expansion Process } \\ S & =\text { distance along the fiber, inch } \\ {[\boldsymbol{T}]} & =\text { transformation matrix } \\ v & =\text { Poisson's ratio } \\ w(s) & =\text { deflection at } s, \text { inch } \\ \epsilon_{a}(s) & =\text { axial strain at } s \\ \epsilon(s) & =\text { strain at } s\end{array}$

${ }^{1}$ Aerospace Engineer, Aerostructures Branch, P.O. Box 273 Edwards, California/Mailstop 48202A, Senior Member AIAA. 


$\begin{array}{ll}\kappa(s) & =\text { curvature at } s, \text { in }^{-1} \\ \Phi_{M} & =\text { eigen-matrix corresponds to master degrees of freedom } \\ \Phi_{S} & =\text { eigen-matrix corresponds to slave degrees of freedom } \\ (*)^{\mathrm{T}} & =\text { transpose of a matrix } \\ (*)^{-1} & =\text { inverse of a matrix }\end{array}$

\section{Introduction}

DAL-TIME measurement of the deflection and slope of aerospace structures in flight is a valuable tool for improving aircraft performance, safety, and efficiency. Potential applications include structural health monitoring, flexible motion control, induced drag reduction through active aerodynamic tuning, real-time aerodynamic load calculation, and virtual display of structure motion. Flight-test methods of deflection measurement can use cameras ${ }^{1}$ and while these methods can be effective for test flight, they are impractical for permanent installation and long term reliability. In addition, they are only able to measure deflection at discrete locations.

Previous research describes at least two methods of calculating internal loads on an aircraft during flight. The Ko Displacement theory, ${ }^{2}$ set forth in (U.S. Patent Number 7,520,176) ${ }^{3}$ and (U.S. Patent Number 7,715,994), ${ }^{4}$ uses closed-form equations to calculate real-time operational loads on complex structures using surface strain data. Another calculation method uses a matrix equation based on the displacement and strain mode shape matrices. ${ }^{5}$ Both of the above-described prior art methods are suitable only for calculating deflection and load values in crosssectional lumps based on the location of the sensors used to measure strain on the surface.

The method described by Moore, ${ }^{6}$ (U.S. Patent Number 7,813,599), includes the steps of deducing curvature and bend radius data for the fiber from the strain data; curve-fitting to obtain curvature and bending direction functions pertaining to the fiber; calculating a torsion function using the bending direction function; and calculating the threedimensional shape of the optical fiber from the combination of the curvature, and bending and torsion functions. Park et al. ${ }^{7}$ uses beam theory and fits a curvature function to a bending needle using a simple second order polynomial fit appropriate for just two sensor locations.

The National Aeronautics and Space Administration (NASA) Helios Prototype was an ultra-light flying wing with a 247-foot wingspan that was developed and tested by NASA in the late 1990s and early 2000s. Due to the light weight and large wingspan of the Helios, it experienced a large dihedral while in flight. During a test flight in 2003, the Helios broke up into the Pacific Ocean after the deformation became too large. Stability analysis near the terminal condition indicated a strong tendency to exhibit over-damped, integrator-type static deflection in the structure due to external loading. This accident emphasized the need for monitoring real-time deflection information on lightweight aircraft. ${ }^{8}$

The light weight and accuracy of fiber optic sensors, such as fiber Bragg gratings (FBGs), make them an ideal choice for aerospace applications. This statement is especially true on lightweight aerospace structures, where conventional strain-gauges and associated cabling would present an issue in both weight and bulk. Recently developed fiber optic strain sensing (FOSS) technology uses a series of FBGs to obtain measurements at intervals as small as every half inch along a fiber and at frequencies of several kHz. ${ }^{9}$ The ability of FBGs to operate at such high frequencies makes them useful for both static and dynamic aerospace applications.

The availability of wing deflection and slope data, and the corresponding internal and external load values, at all element grid points across the structure will allow engineers to undertake more accurate, real-time analyses of both internal and external loads at any point on the structure, and will enable real-time virtual display of wing motion. Real-time internal and external load values over the entire surface of a structure may also find application in structural health monitoring, active flexible motion control, and active induced drag reduction.

At present the above-described prior art methods are suitable only for calculating deflection and load values along singular fibers or in localized areas based on the location of the sensors used to measure strain on the surface. What is needed is a way to compute the deflected shape of an entire three dimensional structure using strain measurements from discrete locations. This would vastly improve the ability to monitor the health and behavior of a complex three dimensional structure such as an aircraft in flight.

It is, therefore, an object of the present study to provide a system and method for calculating wing deflection and slope over the entire surface of a three dimensional structure, as opposed to finite points thereon as in previous research. This paper focuses on a strain-based method that integrates strain data to compute out of plane deflection along fibers, and then uses a finite element (FE) model to interpolate and extrapolate all the deflections and slopes of the entire structure. Two experiments are completed in this study. The first experiment investigates the accuracy of the theory by applying it to a cantilevered rectangular wing model analyzed using the MSC/NASTRAN code (MSC Software Corporation, Newport Beach, California). ${ }^{10}$ The second experiment applies the theory to experimental data

2

American Institute of Aeronautics and Astronautics

Patent Pending: Patent App No. 14/482784 
collected from a test plate fabricated and tested at the NASA Armstrong Flight Research Center (AFRC) in Edwards, California.

\section{Mathematical Background of the Two-step Theory}

The structural dynamics group at NASA AFRC have developed a two-step theory and accompanying software to predict the deflection and slope of an entire structure using strain measurements from discrete locations. Figure 1 shows a block diagram of the overall system architecture. This paper is mainly focused on the deflection analyzer and expansion module. As indicated in the introduction the wing is equipped with FOSS segments for measuring strain at multiple locations on the wing structure. The strain is computed at each (x, y, z) location of the FBG sensors in real time. The system architecture adapted for an aircraft is essentially a computerized feedback loop capable of executing the various software modules, including a strain assembler software module for accumulating, indexing, and storing measured strain values in a strain matrix organized by the FOSS segment from which they were derived. Assembler software then passes the strain matrix to a deflection analyzer which calculates deflection along the optical fibers by the curve fitting techniques in section A.

\section{A. First Step (Deflection Analyzer)}

In the first step, a structure is fit with fiber optic cables that take strain measurements at several points along the length using AFRC FOSS technology. For experimental data, strain measurements along each fiber are divided into segments, and each segment is curve-fit using a piecewise least-squares method in order to minimize measurement noise. After noise reduction, an Akima spline is run through the strain data and is numerically integrated twice to compute the slope and deflection along each fiber. The first step can be summarized as follows:

1. Fit the strain/offset (or curvature) data using the piecewise least-squares curve fitting method to minimize noise in measured data. A coordinate system used in this study is shown in Fig. 2.

2. Obtain a cubic spline function using re-generated curvature data points as shown in Fig. 3,

$$
\frac{d^{2} w(s)}{d s^{2}}=\kappa(s)=-\epsilon(s) / c(s)
$$

where, $\epsilon(s)$ and $c(s)$ are strain and vertical offset values at $s$, respectively, and $s$ is along the fiber direction. A small motion assumption is used in Eq. (1). In Fig. 2, the radius of the fiber is assumed to be small enough compared with offset distance $c(s)$.

3. Integrate the fitted spline function to get slope data: $\frac{d w(s)}{d s}$ (slope in fiber direction).

4. Obtain a cubic spline function using computed slope data.

5. Integrate the fitted spline function to get the deflection data: $w(s)$

The calculated deflection data $w(s)$ along each FOSS segment is then passed to an expansion module which expands the calculated deflection data to all points along the three dimensional wing surface. This expansion procedure is explained in section $\mathrm{B}$.

\section{B. Second Step (Expansion Module)}

In the second step, computed deflection along the fibers is combined with a FE model of the structure in order to interpolate, and extrapolate the deflection and slope of the entire structure through the use of System Equivalent Reduction and Expansion Process (SEREP) ${ }^{11}$ Re-arrange all the degrees of freedom (DOF) in the FE model as Eq. (2):

$$
\{\boldsymbol{q}(\boldsymbol{t})\}=\left\{\begin{array}{c}
\boldsymbol{q}_{M}(\boldsymbol{t}) \\
\boldsymbol{q}_{S}(\boldsymbol{t})
\end{array}\right\}
$$

where, $\left\{\boldsymbol{q}_{\boldsymbol{M}}(\boldsymbol{t})\right\}$ is the master DOF. In this approach, deflections and slopes along the fiber obtained from the first step are defined as the master DOF. The rest of the deflections and slopes all over the structure are defined as slave DOF, $\left\{\boldsymbol{q}_{\boldsymbol{S}}(\boldsymbol{t})\right\}$. Consider the following coordinate transformation for the model reduction and expansion techniques as Eq. (3):

$$
\left\{\begin{array}{c}
\boldsymbol{q}_{M}(t) \\
\boldsymbol{q}_{S}(\boldsymbol{t})
\end{array}\right\}=[\boldsymbol{T}]\left\{\widetilde{\boldsymbol{q}}_{M}(\boldsymbol{t})\right\}
$$


where, $\left\{\widetilde{\boldsymbol{q}}_{\boldsymbol{M}}(\boldsymbol{t})\right\}$ is the measured master DOF which was computed from the first step. From SEREP, the transformation matrix $[\boldsymbol{T}]$ can be expressed as Eq. (4):

$$
[\boldsymbol{T}]=\left[\begin{array}{l}
\Phi_{M}\left(\Phi_{M}^{\mathrm{T}} \Phi_{M}\right)^{-1} \Phi_{M}^{\mathrm{T}} \\
\Phi_{S}\left(\Phi_{M}^{\mathrm{T}} \Phi_{M}\right)^{-1} \Phi_{M}^{\mathrm{T}}
\end{array}\right]
$$

where, $\Phi_{M}$ and $\Phi_{S}$ are eigen-matrices corresponding to master and slave DOFs, respectively. These eigen-matrices are computed from the FE model of the test article using the MSC/NASTRAN code. From Eqs. (2) through (4), all the DOF in the structure can be computed using Eq.(5):

$$
\{\boldsymbol{q}(\boldsymbol{t})\}=\left\{\begin{array}{l}
\boldsymbol{q}_{\boldsymbol{M}}(\boldsymbol{t}) \\
\boldsymbol{q}_{S}(\boldsymbol{t})
\end{array}\right\}=\left[\begin{array}{l}
\boldsymbol{\Phi}_{M}\left(\boldsymbol{\Phi}_{M}^{\mathrm{T}} \boldsymbol{\Phi}_{M}\right)^{-1} \boldsymbol{\Phi}_{M}^{\mathrm{T}} \\
\boldsymbol{\Phi}_{S}\left(\boldsymbol{\Phi}_{M}^{\mathrm{T}} \boldsymbol{\Phi}_{M}\right)^{-1} \boldsymbol{\Phi}_{M}^{\mathrm{T}}
\end{array}\right]\left\{\widetilde{\boldsymbol{q}}_{M}(\boldsymbol{t})\right\}
$$

The first and second steps are summarized in Fig. 4. While several methods have been developed to compute deflection along single fibers, the innovative ability of the method proposed in this study to predict the deflection and slope of an entire structure makes it an excellent candidate for monitoring the health and behavior of a complex aircraft in flight.

\section{Results and Discussions}

The theory is first validated on a computational model, a cantilevered rectangular plate. The theory is then applied to test data from a cantilevered swept-plate model. Computed results are compared with finite element results, results using another strain-based method, and photogrammetry data.

\section{A. Computational Validation}

For initial validation and refinement of this theory, three test load cases are run on a rectangular plate FE model created and analyzed using the MSC/NASTRAN and ZAERO (Zona Technology Inc., Scottsdale, Arizona) ${ }^{12}$ codes. The model has a uniform chord length of 4.56 inches, a span length of 11.5 inches, a thickness of 0.065 inches as shown in Fig. 5(a). The material property is assigned a Young's modulus, $E$, of 9.848 Msi; a Poisson's ratio, $v$, of 0.3529 ; and a mass density of $0.1117 \mathrm{lb} / \mathrm{in}^{3} .^{13}$ To represent fiber optic strain sensors, the model is fit with 22 beam elements that compute axial strain along the length of the wing. Because strain measurements come directly from the FE model solution, no piecewise least squares curve-fitting is necessary to eliminate noise.

Three load cases are used: a uniform 1g load, shown in Fig. 5(b); a wing tip torsion load, shown in Fig. 5(c); and an aerodynamic load corresponding to $1^{\circ}$ angle of attack at Mach 0.715 and dynamic pressure of 1.4 psi, shown in Fig. 5(d). For each configuration, deflection and slope are computed over the entire structure and compared with the deflection and slope calculated by the MSC/NASTRAN code directly. In case of the last load case, ZAERO code is used to create trimmed aerodynamic load vectors at Mach 0.715 .

\section{A.1 Under $1 \mathrm{~g}$ Load}

Figure 6(a) shows the curvature distribution for fibers 1 and 11 computed by the MSC/NASTRAN code and the two-step approach after the first step under a $1 \mathrm{~g}$ load. Corresponding wing deflections along the fibers 1 and 11, and over the FE model are shown in Figs. 6(b) and 6(c), respectively. Wing tip deflections along the fibers 1, 3, 5, 7, 9, and 11 are given in Table 1. Target data in this table are computed using the MSC/NASTRAN code. As shown in Table 1, the wing tip deflection errors in this sample problem under a $1 \mathrm{~g}$ load are equal to and less than $0.06 \%$ and $0.8 \%$ after the first and the second steps, respectively. In this study, strain sensors are located quadratically toward the root of the wing in order to yield a more accurate result for a given number of sensors. For each fiber, a total of 50 strain sensors are used in this rectangular wing problem.

Figure 6(d) shows wing slope in roll direction along the fibers 1 and 11, respectively. Wing tip slope along the fibers 1, 3, 5, 7, 9, and 11 are given in Table 2. Similar trends occurred in the slope data as had in the deflection data. Errors of the wing tip slope under a $1 \mathrm{~g}$ load are $0.1 \%$ and $1.3 \%$ after the first and the second steps, respectively. In general, normalized wing tip slope error for a given setup is roughly twice larger than the corresponding deflection error. Relatively small computation errors are observed in the case of the $1 \mathrm{~g}$ load condition. 
A.2 Under Wing Tip Torsion Load (1 lb upward at the leading-edge and $1 \mathrm{lb}$ downward at the trailing-edge)

Figure 7(a) shows the curvature distribution for fibers 1, 3, 5, 7, 9, and 11 computed by the MSC/NASTRAN code and the two-step approach after the first step under the wing tip torsion condition. Corresponding wing deflections after the first step and over the FE model after the second step are shown in Figs. 7(b) and 7(c), respectively. Figure 7(d) shows wing slope in roll direction along the fibers 1, 3, 5, 7, 9, and 11 after the first step. Wing slopes are in excellent agreement with the target MSC/NASTRAN results after the first step.

Wing tip deflections and roll slopes along the fibers 1, 3, 5, 7, 9, and 11 after the first and the second steps are given in Tables 3 and 4, respectively. The second step in these tables are based on the first 50 modes. The number of modes in the second step is selected based on the convergence study in this section. The wing tip deflection errors are $1.9 \%$ and $1.6 \%$ after the first and the second steps, respectively.

The effect of the number of modes on the wing deflection and slopes are studied and results are shown in Figs. 8 through 10. Wing deflections are not affected too much on the number of modes as shown in Fig. 8. However in Fig. 9, wing slopes in the roll direction near the leading-edge of the wing tip section are noticeably affected. Torsional deformation due to a concentrated load at the wing tip is difficult to fit with a small number of modes. When the total number of modes for the second step increases, then this wiggling near the leading-edge of the wing tip becomes smoother. Due to the same reason, wing slopes in the pitch direction near the leading-edges of the wing tip section in Fig. 10 are affected by the number of modes for the second step. Wing slopes in the pitch direction are not computed during the first step. Compare the Figure 10(a) spread of data near the leading-edge of the wing tip section to that of Fig. 10(d).

Target wing tip slopes computed using the MSC/NASTRAN code are compared with the corresponding computed values in Tables 4 and 5 . As shown in Table 4, the maximum of $0.12 \%$ error in the wing tip slope in the roll direction becomes a second step maximum of $-7.9 \%$ error. A maximum error of $6.1 \%$ is observed for the wing slope in the pitch direction as shown in Table 5. In this study, $1 \mathrm{lb}$ upward and $1 \mathrm{lb}$ downward loads are applied to simulate wing tip torsion. Relatively large computation errors compared to the $1 \mathrm{~g}$ load condition are observed near the applied load point. It should be noted that only the second step is a FE model dependent approach.

\section{A.3 Under $1^{\circ}$ Angle of Attack at Mach 0.715}

In this study, the ZAERO code is used to have aeroelastic wing deformations. Figure 11(a) shows pressure distribution over the rectangular wing under $1^{\circ}$ angle of attack at Mach 0.715 and a dynamic pressure of 1.4 psi. Pressure in this figure is splined to have an applied aerodynamic load vector at the structural grid points as shown in Fig. 11(b). The MSC/NASTRAN code is used to compute target strain distributions, as shown in Fig. 5(d); and the target and computed curvature distributions for fibers 1, 5, 9, 13, 17, and 21 after the first step are shown in Fig. 12(a). In the case of a two nodes beam element, strains are calculated at the center of each beam, and therefore, extrapolation of curvature is needed at two end points of each fiber. The length of a beam element near the wing tip area is relatively large, and therefore, small extrapolation errors are observed at the wing tip section.

The $\mathrm{Z}$ deflections along each fiber from the first step are used in the second step to compute wing deflections and slopes at all the grid points in the FE model. Three dimensional wing deformation shape is shown in Fig. 12(b). Figure 13 shows a comparison between target and computed wing deformation. In this figure, it can be concluded that not only $\mathrm{Z}$ deflection, but also $\mathrm{X}$ and $\mathrm{Y}$ deflections; and roll, pitch, and yaw slopes all have excellent matching with target values. Correlations at the wing tip section are summarized in Table 6 . The maximum relative error for $\mathrm{Z}$ deflection after the second step is $0.09 \%$. On the other hand, maximum relative errors for $\mathrm{Y}$ and $\mathrm{X}$ deflections are $0.28 \%$ and $-3.2 \%$, respectively. A similar relative error trend is also observed for slope results in Table 6 . The maximum relative error for slope in roll is $0.28 \%$ as with the $\mathrm{Y}$ deflection; and the maximum relative error for slope in pitch is $-3.2 \%$, the same as the $\mathrm{X}$ deflection. In yaw direction, Fig. 13(f), target and computed results are essentially zero. It should be noted in Table 6 that the small $\mathrm{Z}$ deflection errors caused by extrapolation at the wing tip section after the first step are smoothed after the second step. Therefore, the average relative error $0.07 \%$ after the first step becomes $0.04 \%$ after the second step.

\section{B. Experimental Testing}

Once the theory has been validated on the computational model in the previous section, the theory is applied to experimental data from a test plate fabricated and tested at NASA AFRC. The test plate has a uniform chord length of 12 inches, leading- and trailing-edge lengths of 50 inches, a thickness of 0.19 inches, and is backward-swept at a $45^{\circ}$ angle. Test plate is made of 6061-T6 aluminum with a Young's modulus of $10 \mathrm{Msi}$, a Poisson's ratio $v$ of 0.3, and a mass density of $0.098 \mathrm{lb} / \mathrm{in}^{3}$. A FE model with two load cases and the test setup are shown in Figs. 14 and 15, respectively. 
The top and bottom surfaces of the test plate are each fitted with three fiber optic cables. Each surface has one fiber located 0.5 inches from the leading-edge, one located 0.5 inches from the trailing edge, and one located at the mid-chord. Along each fiber are white dots used for photogrammetry imaging as shown in Fig. 15. Load cases are applied by hanging calibrated weights to different points along the leading and trailing edges of the plate. Test data under a leading-edge and uniform load cases, as shown in Fig. 14, are used in this study.

It is recommended that the fibers on an experimental model should be extended all the way to the root to minimize the computation error since the boundary conditions are applied at the root section of a wing. One correction that needs to be made to the model is due to large deflection. For a beam in pure bending, the curvature is given by Eq. (6) where $\epsilon(s)$ is the surface strain, and $c(s)$ is the distance from the neutral axis to the surface.

$$
\kappa(s)=-\epsilon(s) / c(s)
$$

For the experimental model, the large deflection created an axial load in addition to a bending load. The resulting strain is given by Eq. (7).

$$
\epsilon(s)=-\kappa(s) c(s)+\epsilon_{a}(s)
$$

To account for the non-linear effect, the curvature yielded by Eq. (6) cannot be integrated directly to compute deflection and slope. Averaging the curvatures calculated by using each fiber individually eliminates the effect of the axial load. This computation is performed after curve-fitting each set of data individually to minimize noise.

To reduce noise, each set of raw strain measurements is divided into five span-wise segments which are each fit with cubic polynomials calculated using piecewise least squares curve fitting. An actual fit along the upper and lower leading-edge fibers are shown in Fig. 16. Cubic polynomials are used because they are capable of following the data without creating too much wiggling. Five segments are chosen because it is the lowest number of segments that allows the cubic polynomials to reasonably follow the data.

Complete results can be found in Figs. 17 and 18 which show the deflection computed after the first step and the second step with 10 modes. Results are compared to photogrammetry data and also to the solution computed by Bakalyar and Jutte ${ }^{14}$ along each fiber. Results along the fibers are similar in accuracy to the referenced results, ${ }^{14}$ and the general results smoothly interpolate the entire surface. This smoothness is especially apparent in Fig. 19, which shows a close-up of the result from the FE model after the second step with 10 modes. Along the fibers, computed results after the first step are as or more accurate than the referenced results. Table 7 shows the computed tip deflection along each fiber compared to the deflection measured using photogrammetry. In general, the computed results are least accurate along the trailing-edge fiber. The maximum absolute error of about 0.20 inches occurred on the trailing-edge fiber during the leading-edge and uniform load cases. The maximum relative error of $-3.8 \%$ occurred on the trailing-edge fiber during the leading-edge load case.

Most of the error is experienced on the trailing-edge fiber, and it is clear from the data that the error begins near the root and is propagated down the length of the wing. A possible explanation for this error at the root is the steep gradient in strain that occurs in this region as shown in Fig. 20. It should be noted that the largest strain gradient exists near the trailing-edge of the wing root section. Due to the limited number of strain sensors that are used, it is likely that the data obtained near the root are too coarse to accurately integrate the strain along the trailing edge fiber.

\section{Conclusion}

The two-step approach for computing all the degrees of freedom in a structural FE model from measured strain along the FOSS is successfully applied to a cantilevered rectangular wing model and a test plate. The first experiment investigates the accuracy of the theory by applying it to a cantilevered rectangular wing model analyzed using the MSC/NASTRAN and ZAERO codes. The wing tip deflection errors under a $1 \mathrm{~g}$ load are equal to or less than $0.06 \%$ and $0.8 \%$ after the first and second steps, respectively. Errors of the wing tip slope in roll direction under a $1 \mathrm{~g}$ load are $0.1 \%$ and $1.3 \%$ after the first and second steps, respectively.

On the other hand, the wing tip deflection errors under a wing tip torsion load are $1.9 \%$ and $1.6 \%$ after the first and second steps, respectively. If we exclude the leading-edge fiber case, then the maximum errors are $-0.61 \%$ and $0.30 \%$ after the first and second steps, respectively. Wing slope errors in the pitch and roll directions are usually twice larger than the wing deflection errors. Maximum errors of $0.12 \%$ and $7.9 \%$ are observed for errors in roll direction after the first and second steps, respectively. The larger error for the results from the second step is mainly because the torsional deformation, due to a concentrated load at the leading-edge of wing tip, is difficult to fit with a 
small number of modes. Therefore, a large number of modes are needed to fit the plate deflection during the second step. This statement is also true for wing slope in the pitch direction which has a maximum error of $6.1 \%$.

The two-step approach is tested with aeroelastic wing deformation in the last load case. Target aeroelastic deformations are obtained from MSC/NASTRAN and ZAERO codes. All six DOF computed and compared with target values. Maximum deflection errors in X, Y, and Z directions are $-3.2 \%, 0.28 \%$, and $0.09 \%$, respectively, and maximum slope errors in the roll and pitch directions are $0.28 \%$ and $-3.2 \%$, respectively. It should be noted that all DOF in the FE model of the rectangular wing are computed based only on the wing deflection in the $\mathrm{Z}$ direction computed from the first step. These computed DOFs have excellent matching with target values.

The second experiment applies the theory to experimental data collected from a test plate fabricated and tested at the NASA AFRC. The deflections calculated from the experimental model are extremely accurate. Average absolute errors at the tip are less than $1.7 \%$ and $1.9 \%$ after the first and second steps, respectively.

\section{Acknowledgments}

The work presented in this paper was funded by the Aero Science and Fixed Wing Projects under the ARMD Fundamental Aeronautics Program. The author would also like to thank an undergraduate student research program student, Mr. David McWilliams, from Rensselaer Polytechnic Institute (Troy, New York) for his support during the summer intern session in 2013.

\section{Tables}

Table 1. Target data versus computed wing deflection in $\mathrm{Z}$ direction at the wing tip section under $1 \mathrm{~g}$ load.

\begin{tabular}{|c|c|c|c|c|c|}
\hline \multirow{2}{*}{ Fiber number } & \multirow{2}{*}{ Target (inch) } & \multicolumn{2}{|c|}{ Computed deflection (inch) } & \multicolumn{2}{c|}{ Relative error (\%) } \\
\cline { 3 - 5 } & & Step 1 & Step 2 & Step 1 & Step 2 \\
\hline 1 & -0.06638 & -0.06634 & -0.06624 & -0.06 & -0.21 \\
\hline 3 & -0.06641 & -0.06641 & -0.06616 & 0.00 & -0.38 \\
\hline 5 & -0.06643 & -0.06644 & -0.06608 & 0.02 & -0.53 \\
\hline 7 & -0.06645 & -0.06646 & -0.06602 & 0.02 & -0.65 \\
\hline 9 & -0.06646 & -0.06647 & -0.06597 & 0.02 & -0.74 \\
\hline 11 & -0.06647 & -0.06648 & -0.06596 & 0.02 & -0.77 \\
\hline
\end{tabular}

Table 2. Target data versus computed wing slope in roll direction at the wing tip section under $1 \mathrm{~g}$ load.

\begin{tabular}{|c|c|c|c|c|c|}
\hline \multirow{2}{*}{ Fiber number } & \multirow{2}{*}{ Target } & \multicolumn{2}{|c|}{ Computed slope } & \multicolumn{2}{c|}{ Relative error (\%) } \\
\cline { 3 - 6 } & & Step 1 & Step 2 & Step 1 & Step 2 \\
\hline 1 & -0.007812 & -0.007817 & -0.007759 & 0.06 & -0.68 \\
\hline 3 & -0.007811 & -0.007818 & -0.007752 & 0.10 & -0.75 \\
\hline 5 & -0.007809 & -0.007817 & -0.007737 & 0.10 & -0.91 \\
\hline 7 & -0.007807 & -0.007815 & -0.007721 & 0.10 & -1.10 \\
\hline 9 & -0.007806 & -0.007813 & -0.007709 & 0.09 & -1.20 \\
\hline 11 & -0.007806 & -0.007813 & -0.007704 & 0.09 & -1.30 \\
\hline
\end{tabular}


Table 3. Target data versus computed wing deflection in $\mathrm{Z}$ direction at the wing tip section under wing tip torsion.

\begin{tabular}{|c|c|c|c|c|c|}
\hline \multirow{2}{*}{$\begin{array}{c}\text { Fiber } \\
\text { number }\end{array}$} & \multirow{2}{*}{$\begin{array}{c}\text { Target } \\
\text { (inch) }\end{array}$} & \multicolumn{2}{|c|}{ Computed deflection (inch) } & \multicolumn{2}{c|}{ Relative error (\%) } \\
\hline & Step 1 & Step 2 with 50 modes & Step 1 & Step 2 with 50 modes \\
\hline 1 & 0.07163 & 0.07024 & 0.07050 & -1.90 & -1.60 \\
\hline 3 & 0.05727 & 0.05709 & 0.05692 & -0.30 & -0.61 \\
\hline 5 & 0.04293 & 0.04292 & 0.04295 & -0.02 & 0.06 \\
\hline 7 & 0.02861 & 0.02862 & 0.02869 & 0.05 & 0.28 \\
\hline 9 & 0.01430 & 0.01431 & 0.01433 & 0.07 & 0.22 \\
\hline 11 & 0.00000 & 0.00000 & 0.00000 & 0.00 & 0.00 \\
\hline
\end{tabular}

Table 4. Target data versus computed wing slope in roll direction at the wing tip section undergoing wing tip torsion.

\begin{tabular}{|c|c|c|c|c|c|}
\hline \multirow{2}{*}{$\begin{array}{c}\text { Fiber } \\
\text { number }\end{array}$} & \multirow{2}{*}{ Target } & \multicolumn{2}{|c|}{ Computed wing slope } & \multicolumn{2}{c|}{ Relative error (\%) } \\
\cline { 3 - 6 } & & Step 1 & Step 2 with 50 modes & Step 1 & Step 2 with 50 modes \\
\hline 1 & 0.006769 & 0.006775 & 0.006457 & 0.093 & -4.60 \\
\hline 3 & 0.005483 & 0.005490 & 0.005712 & 0.120 & 4.20 \\
\hline 5 & 0.004126 & 0.004131 & 0.004337 & 0.110 & 5.10 \\
\hline 7 & 0.002754 & 0.002757 & 0.002734 & 0.120 & -0.71 \\
\hline 9 & 0.001377 & 0.001379 & 0.001268 & 0.120 & -7.90 \\
\hline 11 & 0.000000 & 0.000000 & 0.000000 & 0.000 & 0.00 \\
\hline
\end{tabular}

Table 5. Target data versus computed wing slope in pitch direction after the second step at the wing tip section undergoing wing tip torsion.

\begin{tabular}{|c|c|c|c|}
\hline Fiber number & Target & Computed wing slope with 50 modes & Relative error (\%) \\
\hline 1 & 0.03148 & 0.02956 & -6.10 \\
\hline 3 & 0.03144 & 0.03014 & -4.10 \\
\hline 5 & 0.03138 & 0.03099 & -1.20 \\
\hline 7 & 0.03135 & 0.03141 & 0.19 \\
\hline 9 & 0.03134 & 0.03143 & 0.32 \\
\hline 11 & 0.03133 & 0.03138 & 0.17 \\
\hline
\end{tabular}


Table 6. Target data versus computed wing deformation at the wing tip section under $1^{\circ}$ angle of attack at Mach 0.715.

\begin{tabular}{|c|c|c|c|c|c|}
\hline \multirow{2}{*}{ Fiber number } & \multirow{2}{*}{ Target (inch) } & \multicolumn{2}{|c|}{ Computed X deflection (inch) } & \multicolumn{2}{|c|}{ Relative error (\%) } \\
\hline & & Step 1 & Step 2 with 10 modes & Step 1 & Step 2 with 10 modes \\
\hline 1 & 0.0006927 & N/A & 0.0006703 & N/A & -3.2 \\
\hline 5 & 0.0006975 & N/A & 0.0006776 & N/A & -2.8 \\
\hline 9 & 0.0007029 & N/A & 0.0006936 & N/A & -1.3 \\
\hline 13 & 0.0007047 & N/A & 0.0007081 & N/A & 0.48 \\
\hline 17 & 0.0007035 & N/A & 0.0007144 & N/A & 1.6 \\
\hline 21 & 0.0007023 & N/A & 0.0007143 & N/A & 1.7 \\
\hline \multirow{2}{*}{ Fiber number } & \multirow{2}{*}{ Target (inch) } & \multicolumn{2}{|c|}{ Computed Y deflection (inch) } & \multicolumn{2}{|c|}{ Relative error (\%) } \\
\hline & & Step 1 & Step 2 with 10 modes & Step 1 & Step 2 with 10 modes \\
\hline 1 & -0.003280 & N/A & -0.003282 & N/A & 0.08 \\
\hline 5 & -0.003272 & N/A & -0.003278 & N/A & 0.18 \\
\hline 9 & -0.003260 & N/A & -0.003268 & N/A & 0.26 \\
\hline 13 & -0.003248 & N/A & -0.003257 & N/A & 0.28 \\
\hline 17 & -0.003239 & N/A & -0.003246 & N/A & 0.23 \\
\hline 21 & -0.003235 & N/A & -0.003242 & N/A & 0.20 \\
\hline \multirow{2}{*}{ Fiber number } & \multirow{2}{*}{ Target (inch) } & \multicolumn{2}{|c|}{ Computed Z deflection (inch) } & \multicolumn{2}{|c|}{ Relative error (\%) } \\
\hline & & Step 1 & Step 2 with 10 modes & Step 1 & Step 2 with 10 modes \\
\hline 1 & 0.9280 & 0.9269 & 0.9275 & -0.12 & -0.06 \\
\hline 5 & 0.9085 & 0.9091 & 0.9087 & 0.07 & 0.02 \\
\hline 9 & 0.8889 & 0.8894 & 0.8895 & 0.06 & 0.08 \\
\hline 13 & 0.8691 & 0.8696 & 0.8699 & 0.05 & 0.09 \\
\hline 17 & 0.8493 & 0.8497 & 0.8498 & 0.05 & 0.06 \\
\hline 21 & 0.8296 & 0.8300 & 0.8297 & 0.04 & 0.01 \\
\hline \multirow{2}{*}{ Fiber number } & \multirow{2}{*}{ Target } & \multicolumn{2}{|c|}{ Computed roll slope } & \multicolumn{2}{|c|}{ Relative error (\%) } \\
\hline & & Step 1* & Step 2 with 10 modes & Step 1 & Step 2 with 10 modes \\
\hline 1 & 0.10090 & 0.1010 & 0.10100 & 0.12 & 0.08 \\
\hline 5 & 0.10070 & 0.1016 & 0.10090 & 0.96 & 0.18 \\
\hline 9 & 0.10030 & 0.1012 & 0.10060 & 0.94 & 0.26 \\
\hline 13 & 0.09993 & 0.1009 & 0.10020 & 0.93 & 0.28 \\
\hline 17 & 0.09966 & 0.1006 & 0.09989 & 0.92 & 0.23 \\
\hline 21 & 0.09954 & 0.1004 & 0.09974 & 0.88 & 0.20 \\
\hline \multirow{2}{*}{ Fiber number } & \multirow{2}{*}{ Target } & \multicolumn{2}{|c|}{ Computed pitch slope } & \multicolumn{2}{|c|}{ Relative error (\%) } \\
\hline & & Step 1 & Step 2 with 10 modes & Step 1 & Step 2 with 10 modes \\
\hline 1 & 0.02131 & N/A & 0.02063 & N/A & -3.2 \\
\hline 5 & 0.02146 & N/A & 0.02085 & N/A & -2.9 \\
\hline 9 & 0.02163 & N/A & 0.02134 & N/A & -1.3 \\
\hline 13 & 0.02168 & N/A & 0.02179 & N/A & 0.5 \\
\hline 17 & 0.02165 & N/A & 0.02198 & N/A & 1.5 \\
\hline 21 & 0.02161 & N/A & 0.02198 & N/A & 1.7 \\
\hline \multirow{2}{*}{ Fiber number } & \multirow{2}{*}{ Target } & & uted yaw slope & & solute error \\
\hline & & Step 1 & Step 2 with 10 modes & Step 1 & Step 2 with 10 modes \\
\hline 1 & $2.2 \mathrm{e}-31$ & N/A & $7.9 \mathrm{e}-18$ & N/A & 0.0000 \\
\hline 5 & $1.9 \mathrm{e}-31$ & N/A & 6.6e-18 & N/A & 0.0000 \\
\hline 9 & $1.7 \mathrm{e}-31$ & N/A & $6.1 \mathrm{e}-18$ & N/A & 0.0000 \\
\hline 13 & $1.7 \mathrm{e}-31$ & N/A & $5.7 \mathrm{e}-18$ & N/A & 0.0000 \\
\hline 17 & $1.4 \mathrm{e}-31$ & N/A & 5.9e-18 & N/A & 0.0000 \\
\hline 21 & $1.2 \mathrm{e}-31$ & N/A & $3.3 e-18$ & N/A & 0.0000 \\
\hline
\end{tabular}

*: Roll slope without effect of $\mathrm{X}$ and $\mathrm{Y}$ deflections (These slopes are not used during step 2 computation.) 
Table 7. Computed wingtip deflection versus photogrammetry data.

\begin{tabular}{|c|c|c|c|c|c|c|c|}
\hline & \multirow[b]{2}{*}{$\begin{array}{l}\text { Measured } \\
\text { (inch) }\end{array}$} & \multicolumn{3}{|c|}{ Computed (inch) } & \multicolumn{3}{|c|}{ Relative error (\%) } \\
\hline & & $\begin{array}{c}\text { Bakalyar } \\
\text { and Jutte* }\end{array}$ & Step 1 & $\begin{array}{c}\text { Step } 2 \\
\text { with } 10 \\
\text { modes }\end{array}$ & $\begin{array}{l}\text { Bakalyar } \\
\text { and Jutte }\end{array}$ & Step 1 & $\begin{array}{c}\text { Step } 2 \\
\text { with } 10 \\
\text { modes }\end{array}$ \\
\hline \multicolumn{8}{|c|}{ Leading-edge load } \\
\hline Leading edge fiber & -4.525 & -4.500 & -4.542 & -4.569 & -0.55 & 0.38 & 0.97 \\
\hline Middle fiber & -4.912 & -4.952 & -4.880 & -4.843 & 0.81 & -0.65 & -1.40 \\
\hline Trailing edge fiber & -5.300 & -5.067 & -5.091 & -5.097 & -4.40 & -3.90 & -3.80 \\
\hline \multicolumn{8}{|c|}{ Uniform load } \\
\hline Leading edge fiber & -6.541 & -6.546 & -6.630 & -6.684 & 0.08 & 1.40 & 2.20 \\
\hline Middle fiber & -7.256 & -7.408 & -7.313 & -7.238 & 2.10 & 0.79 & -0.25 \\
\hline Trailing edge fiber & -7.971 & -7.667 & -7.750 & -7.763 & -3.80 & -2.80 & -2.60 \\
\hline
\end{tabular}




\section{Figures}

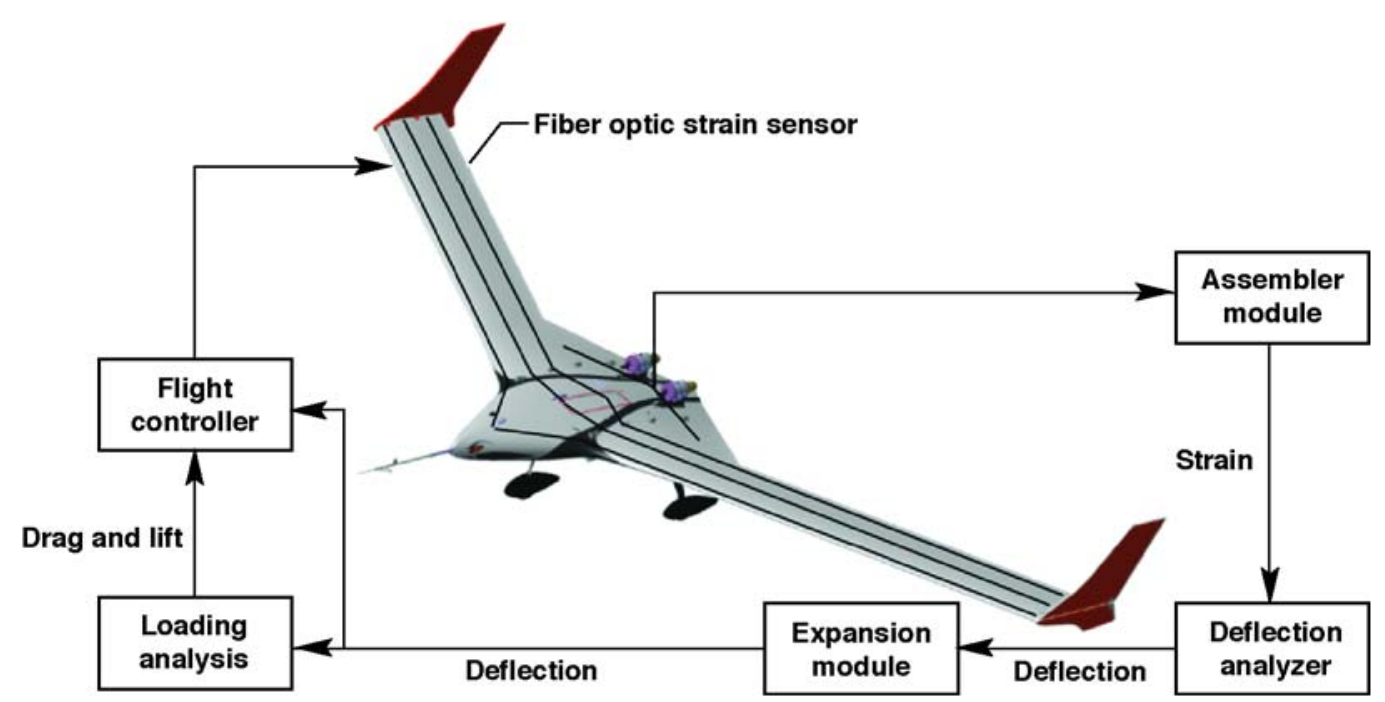

Figure 1. Block diagram of the overall system architecture.

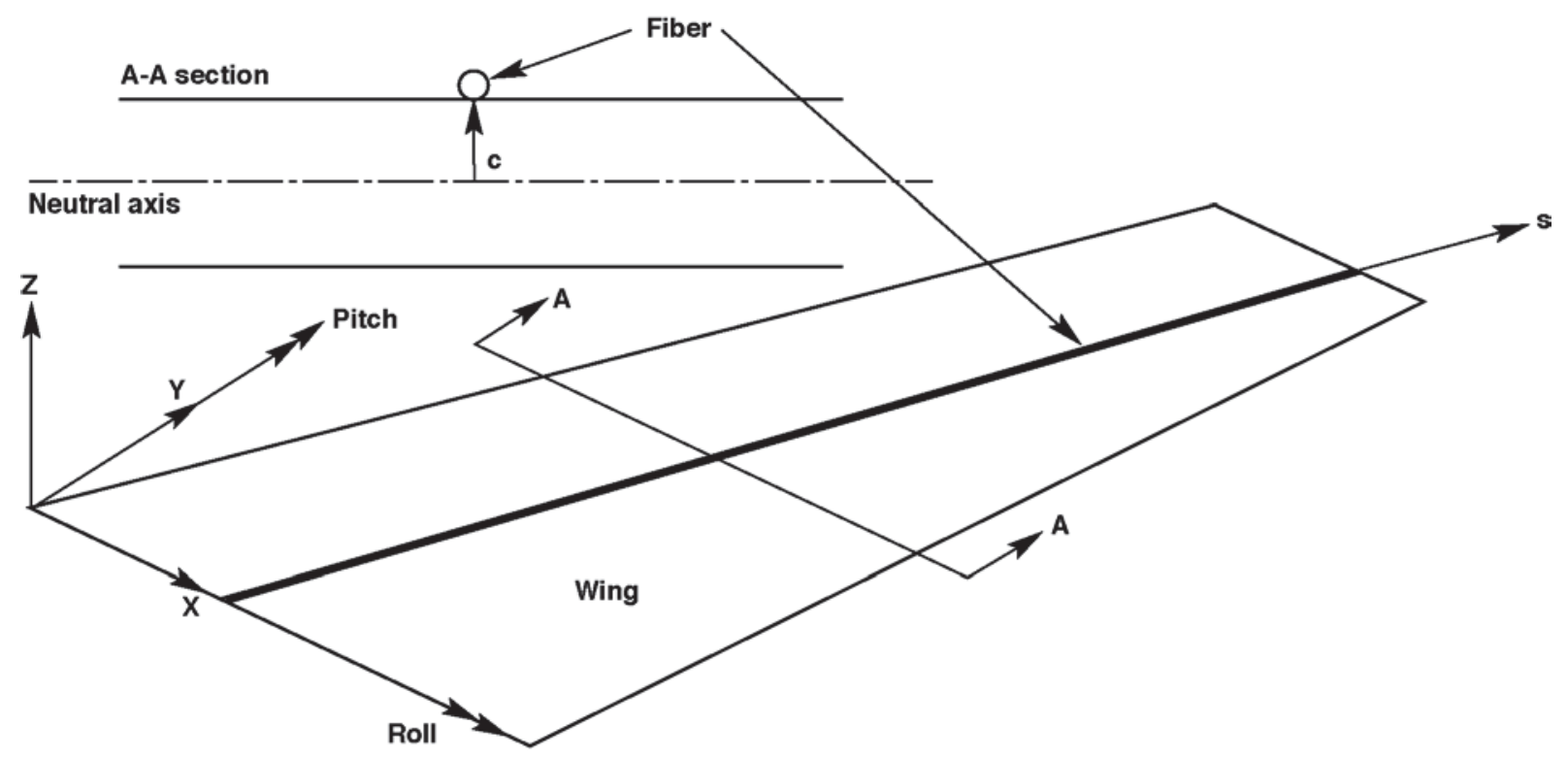

Figure 2. Coordinate system used in this study. 


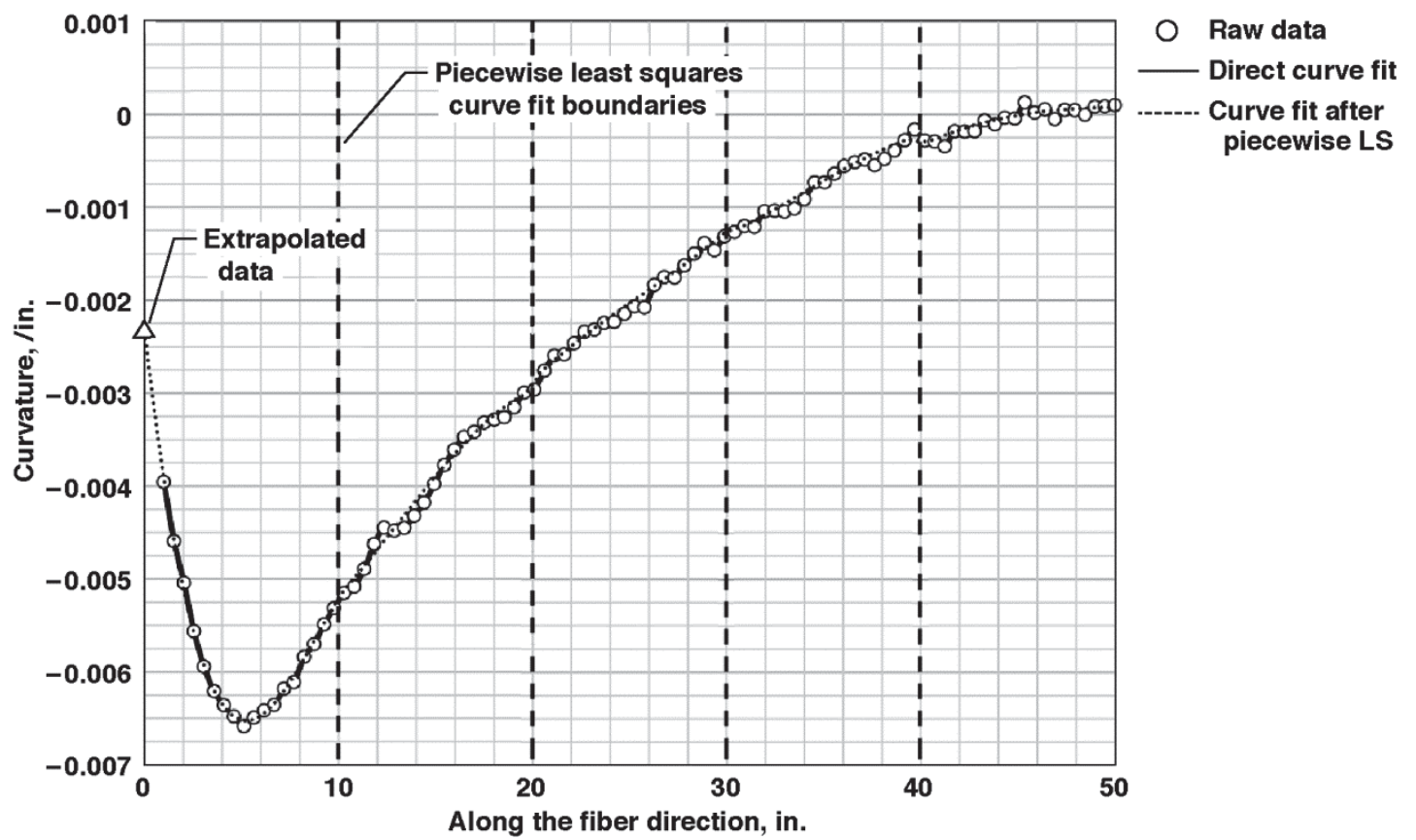

Figure 3. Effect of piecewise least-squares curve fitting before cubic spline curve fitting.

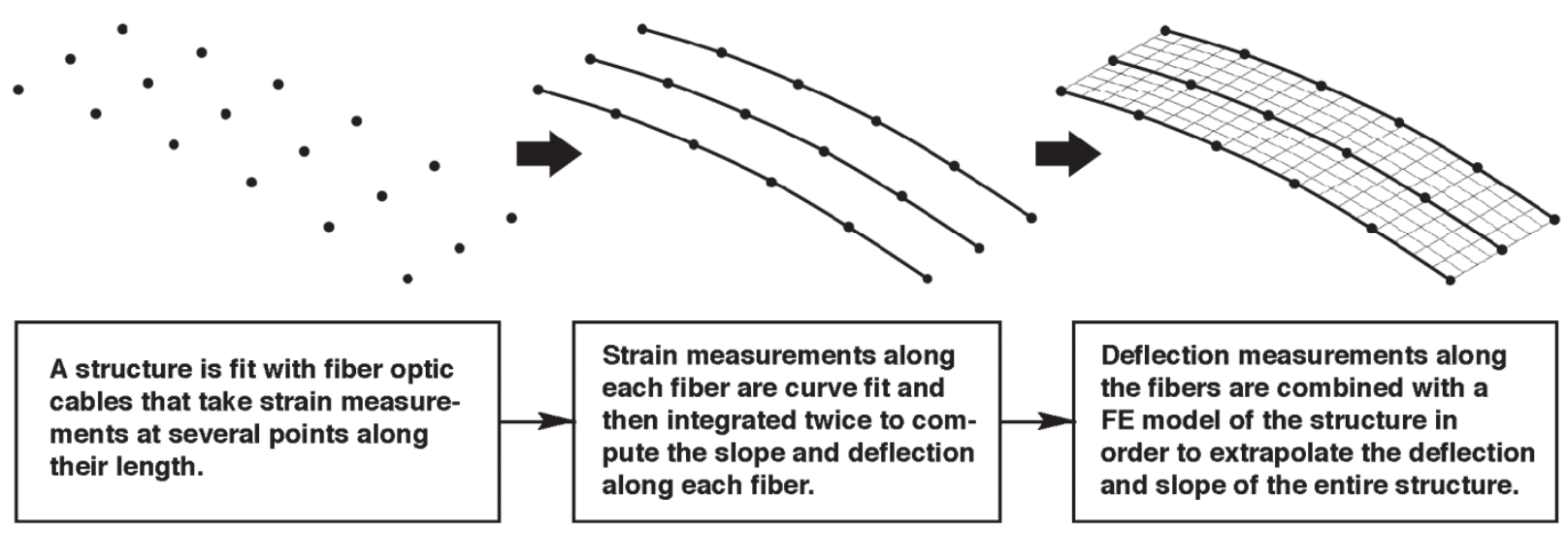

Figure 4. Steps used to compute deflection and slope. 

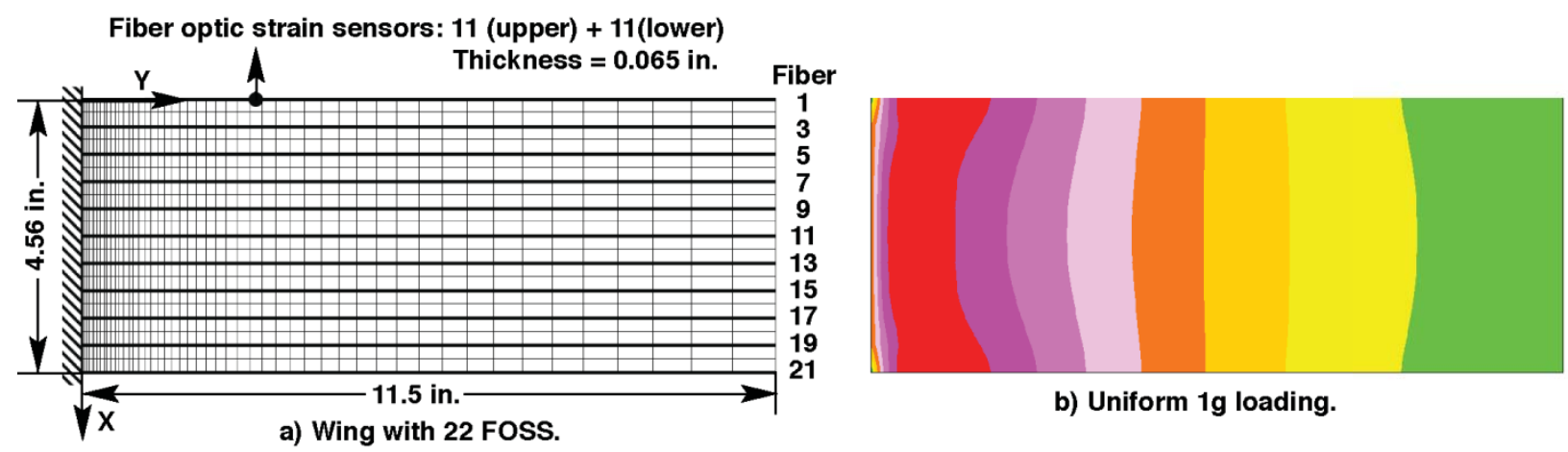

b) Uniform $1 \mathrm{~g}$ loading.

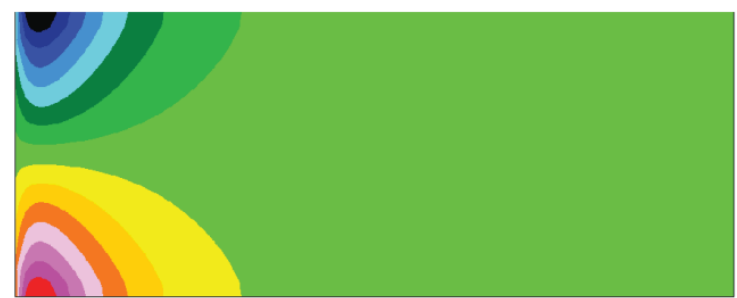

c) Wing tip torsion ( $1 \mathrm{lbf}$ at leading-edge and $-1 \mathrm{lbf}$ at trailing-edge of wing tip section).

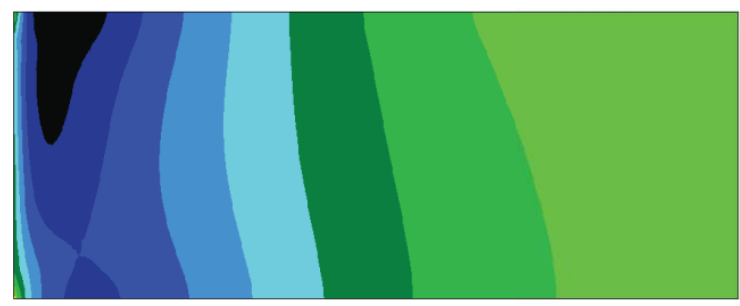

d) Aerodynamic load under $1^{\circ}$ angle of attack at Mach 0.715 .

Figure 5. Cantilevered rectangular wing and strain (y component) distributions over the upper surface of the wing model.

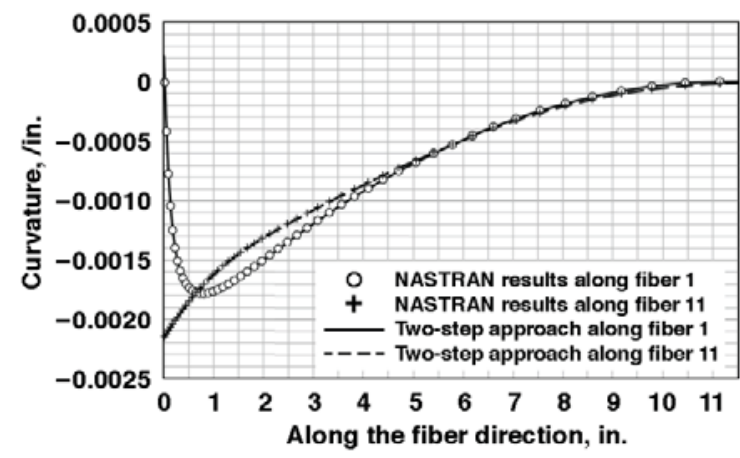

a) Curvature distribution (step 1 results).

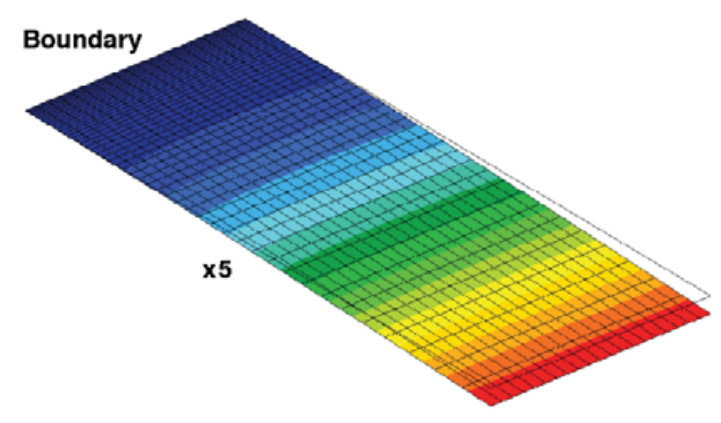

c) Wing deflection over the FE model (step 2 results with 10 modes).

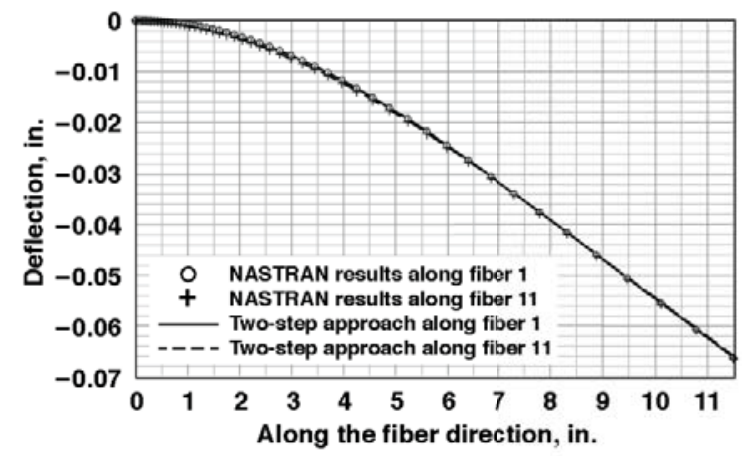

b) Wing deflection (step 2 results with 10 modes).

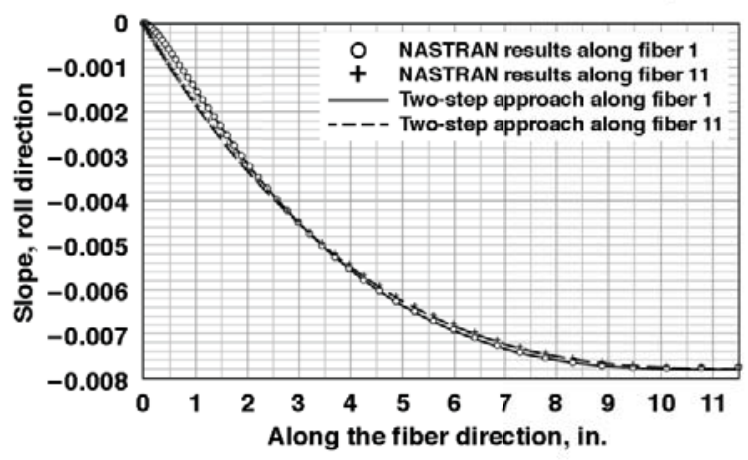

d) Wing span-wise slope (step 2 results with 10 modes).

Figure 6. Curvature, wing deflection, and slopes of the rectangular wing model along Fibers 1 and 11 under a 1 gload. 


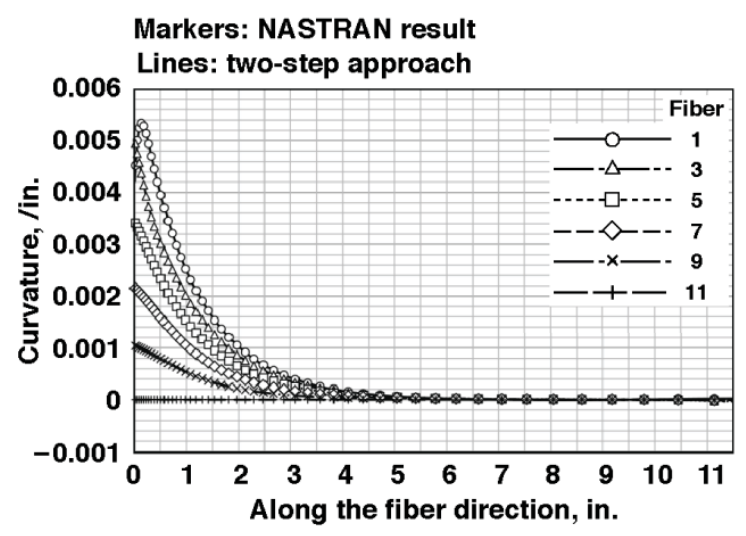

a) Strain distribution (step 1 results).

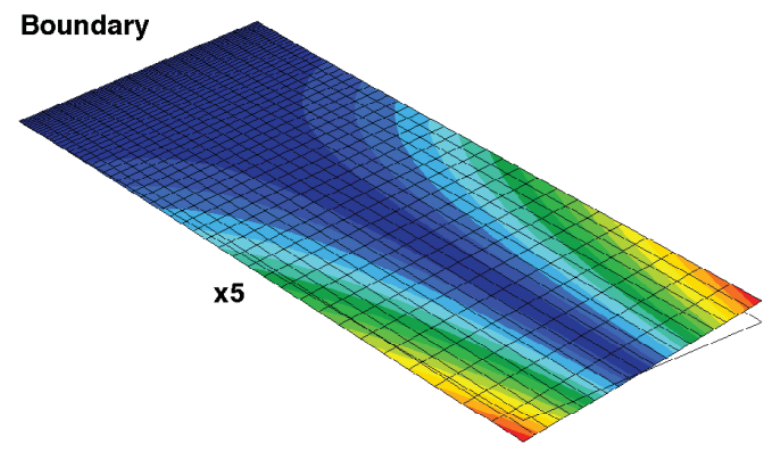

c) Wing deflection over the FE model (step 2 results).

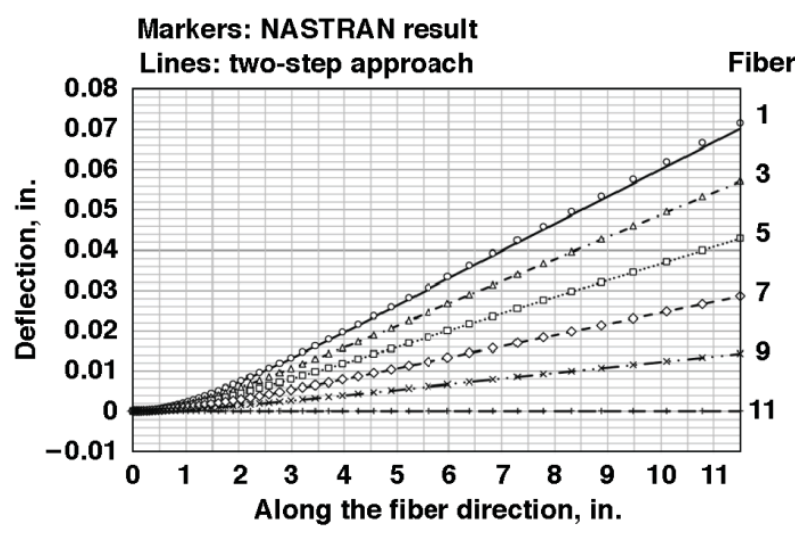

b) Wing deflection (step 1 results).

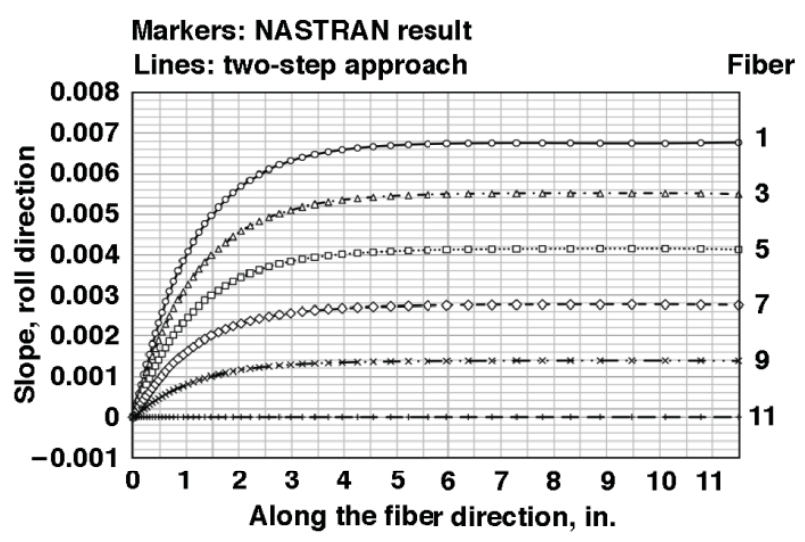

d) Wing span-wise slope (step 1 results).

Figure 7. Curvature distribution, wing deflection, and slopes of the rectangular wing model under a wing tip torsion load. 


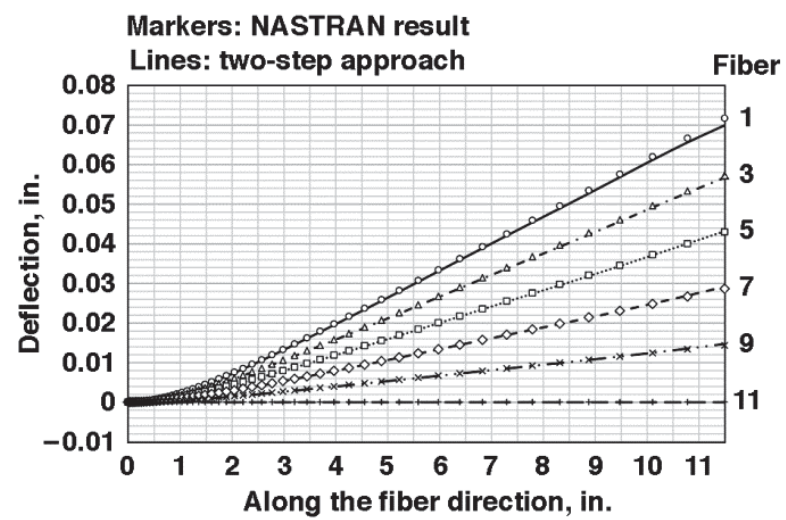

a) Step 2 results with 20 modes.

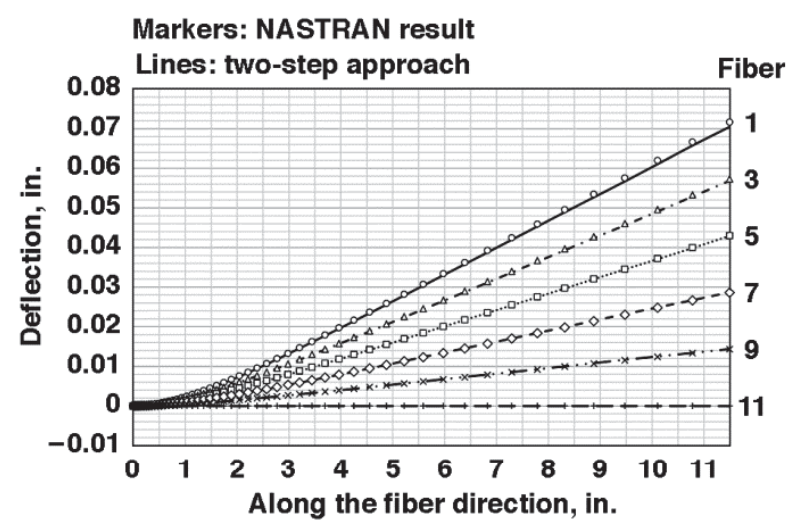

c) Step 2 results with $\mathbf{4 0}$ modes.

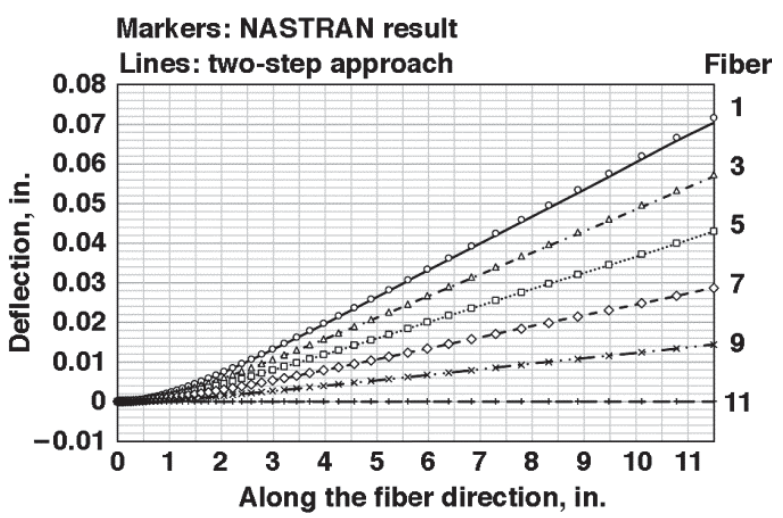

b) Step 2 results with $\mathbf{3 0}$ modes.

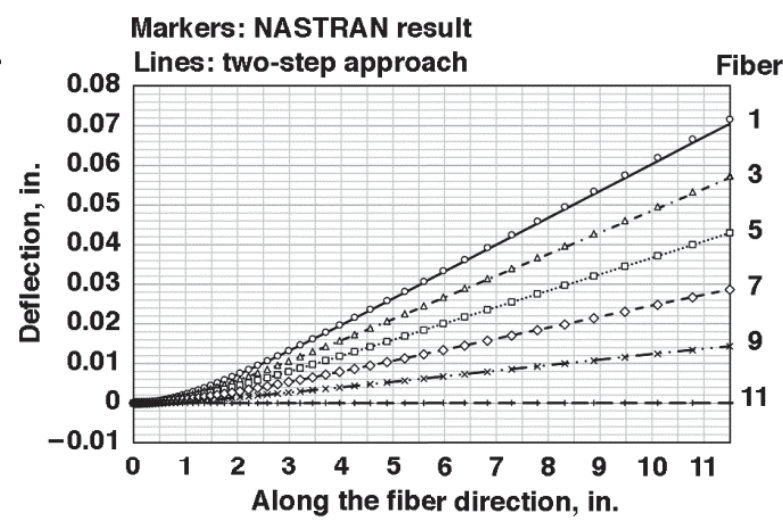

d) Step 2 results with $\mathbf{5 0}$ modes.

Figure 8. Effect of the number of modes on the wing deflection during the second step. 


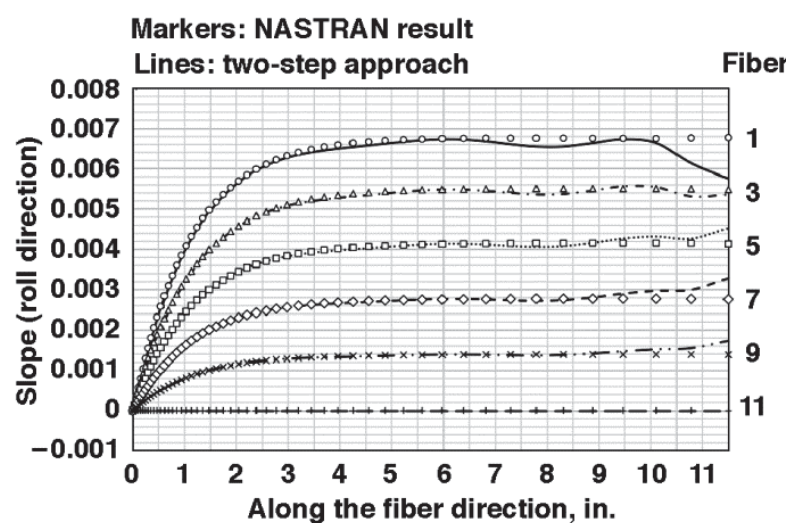

a) Step 2 results with 20 modes.

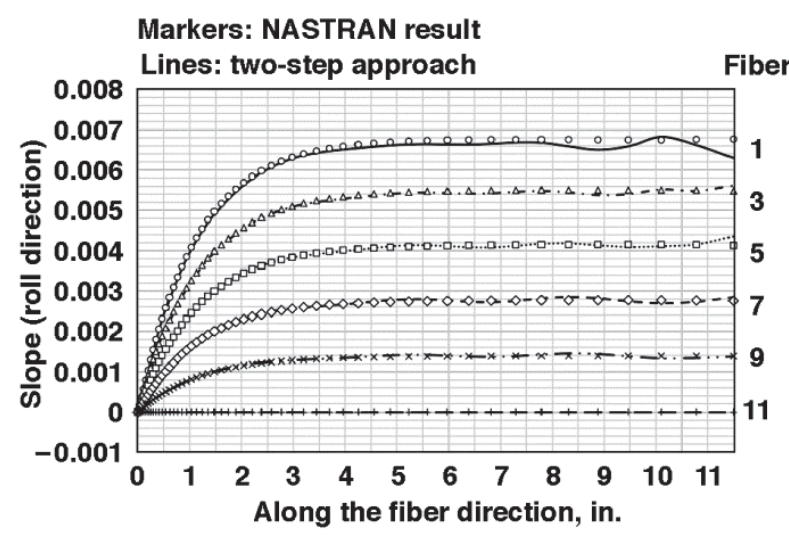

c) Step 2 results with $\mathbf{4 0}$ modes.

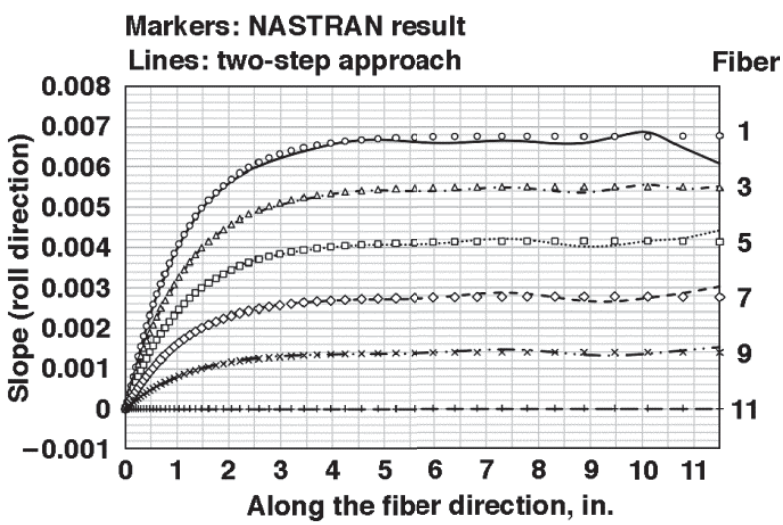

b) Step 2 results with $\mathbf{3 0}$ modes.

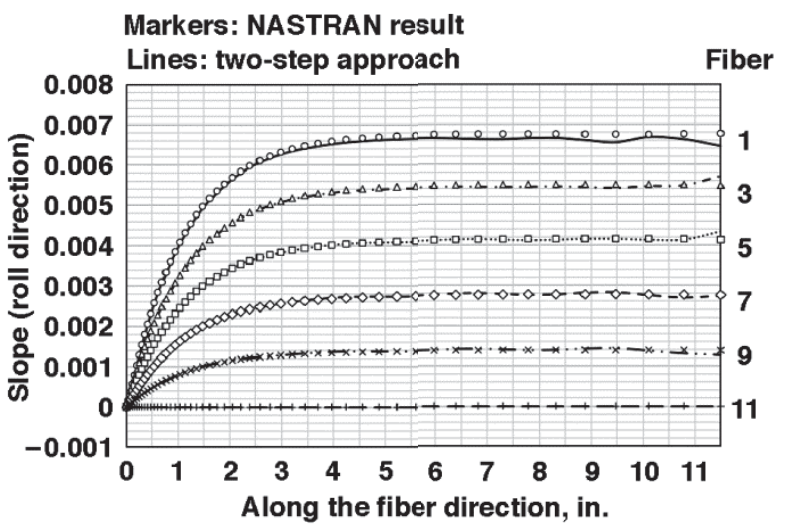

d) Step 2 results with $\mathbf{5 0}$ modes.

Figure 9. Effect of the number of modes on the wing slope in roll direction during the second step. 


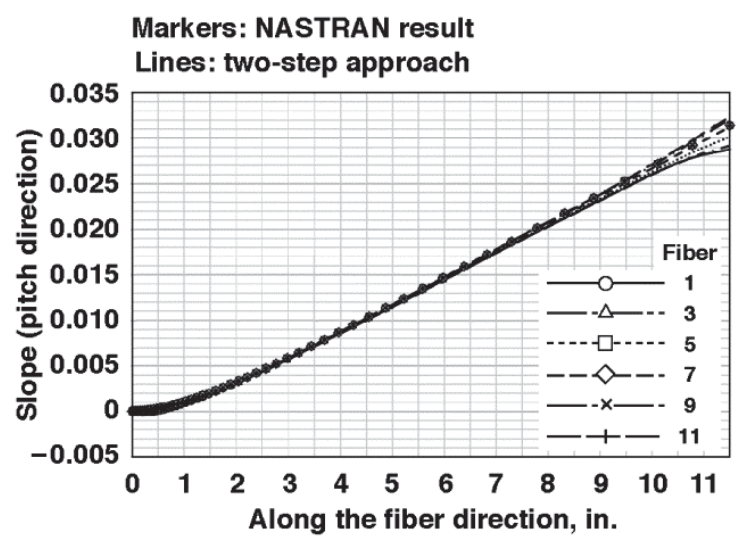

a) Step 2 results with 20 modes.

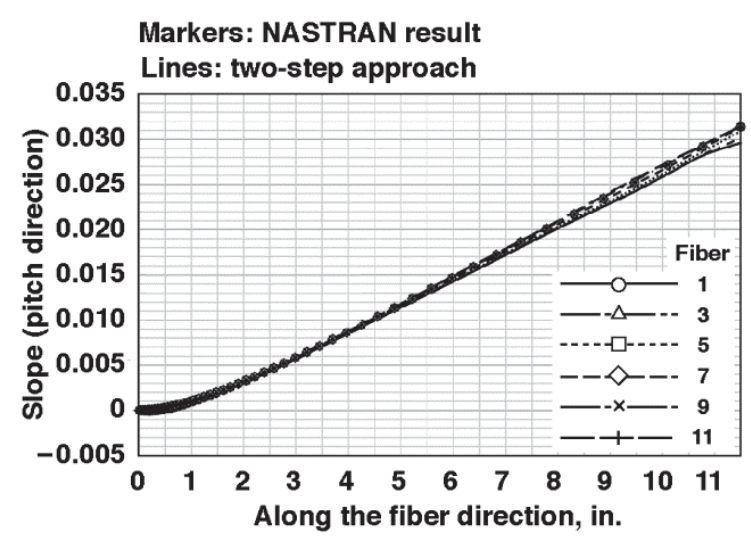

c) Step 2 results with $\mathbf{4 0}$ modes.

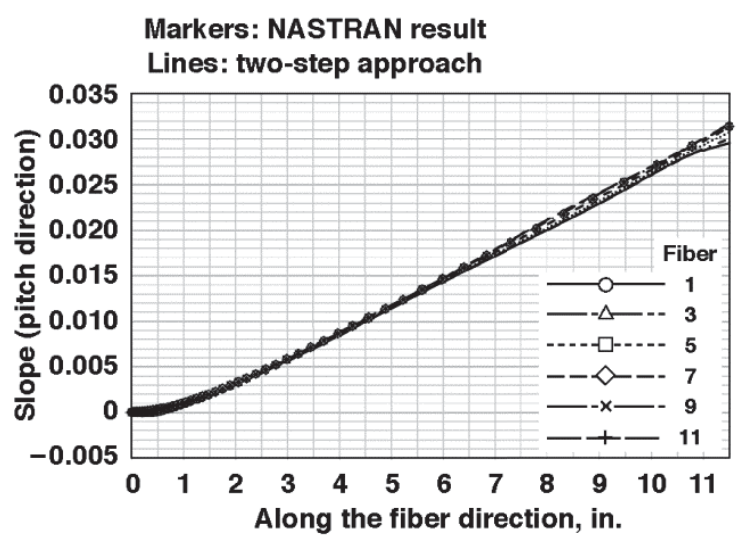

b) Step 2 results with 30 modes.

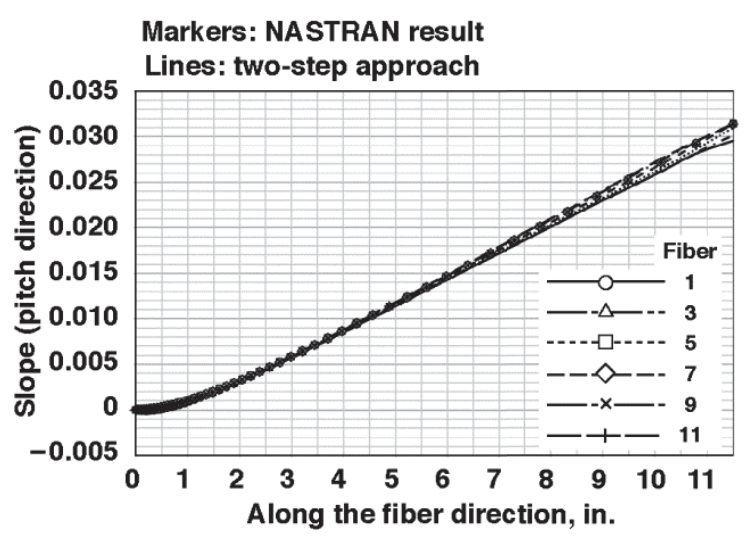

d) Step 2 results with $\mathbf{5 0}$ modes.

Figure 10. Effect of the number of modes on the wing slope in pitch direction during the second step.

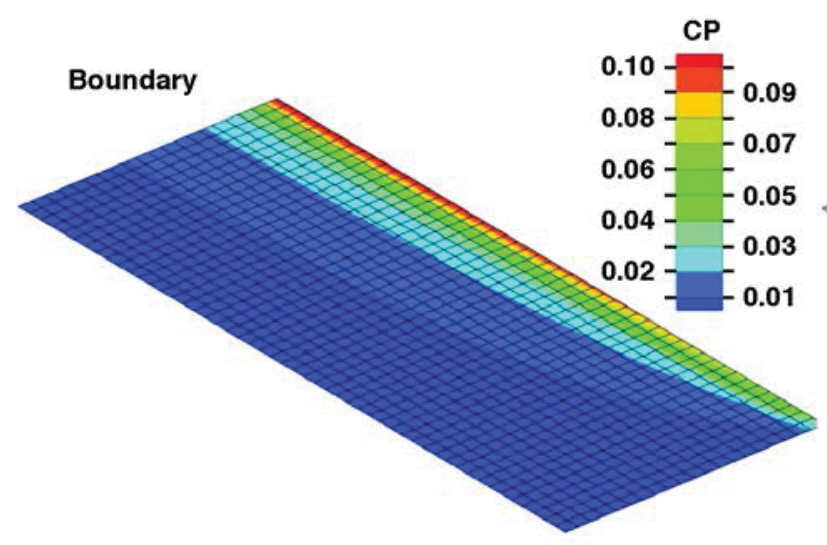

a) Pressure distribution.

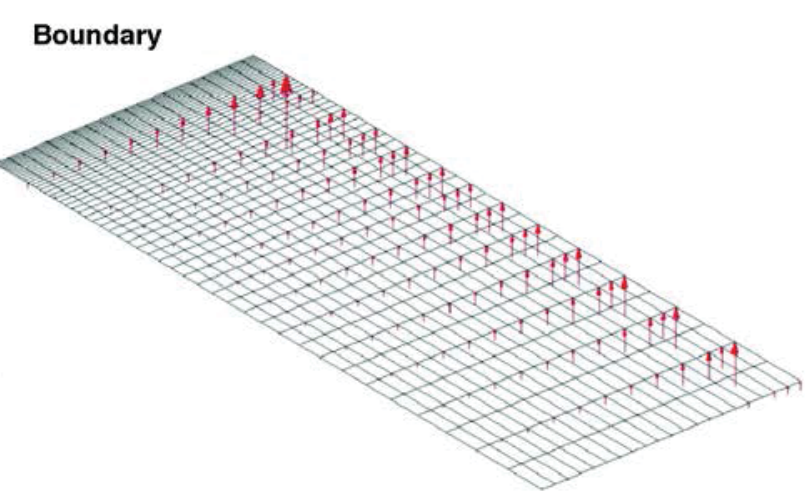

b) Splines load vectors.

Figure 11. Pressure distribution and corresponding splined load vector under $\mathbf{1}^{\circ}$ angle of attack at Mach 0.715 . 


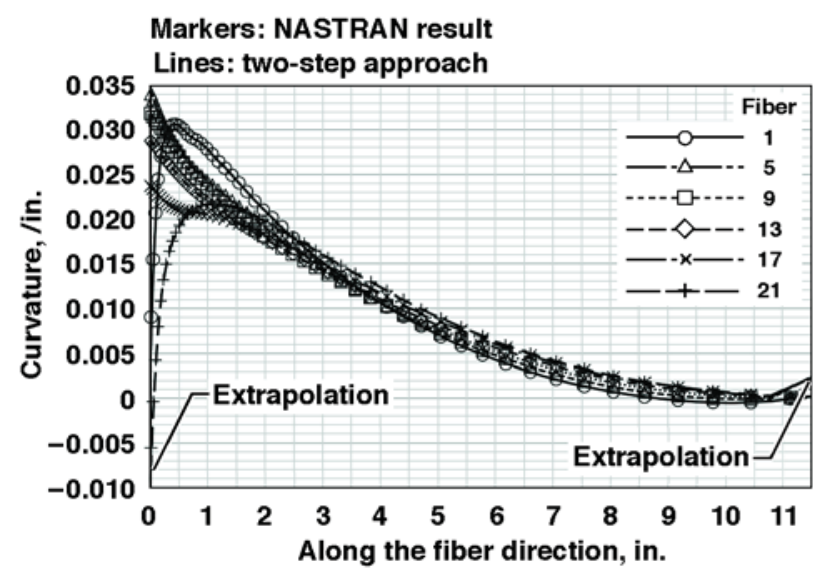

a) Curvature distribution (step 1 results).

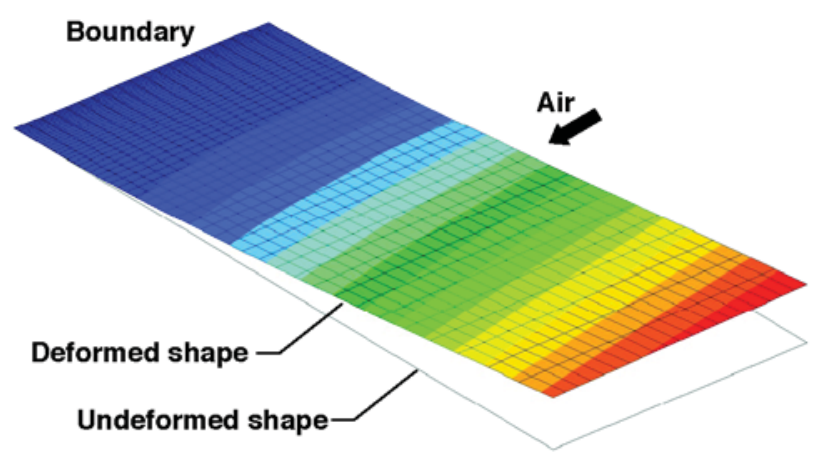

b) Deformed wing shape (step 2 results with 10 modes).

Figure 12. Curvature distribution and deformed wing shape of the rectangular wing under $1^{\circ}$ angle of attack at Mach 0.715 . 


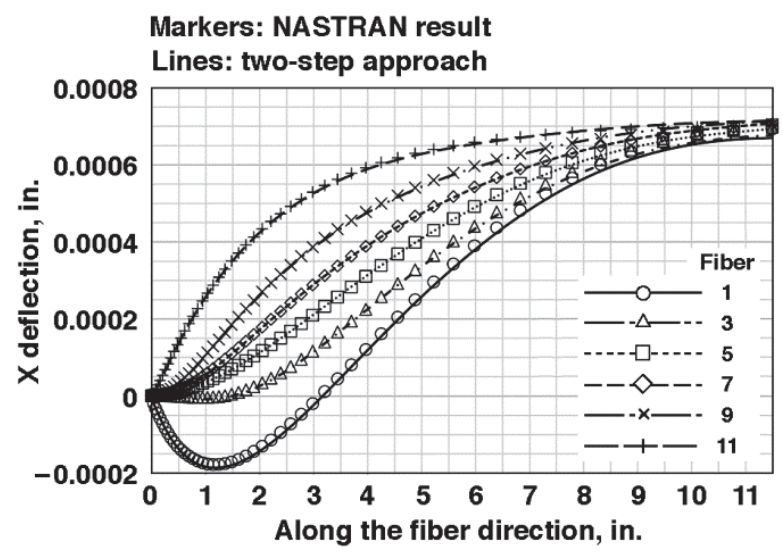

a) $X$ deflection (step 2 results with 10 modes).

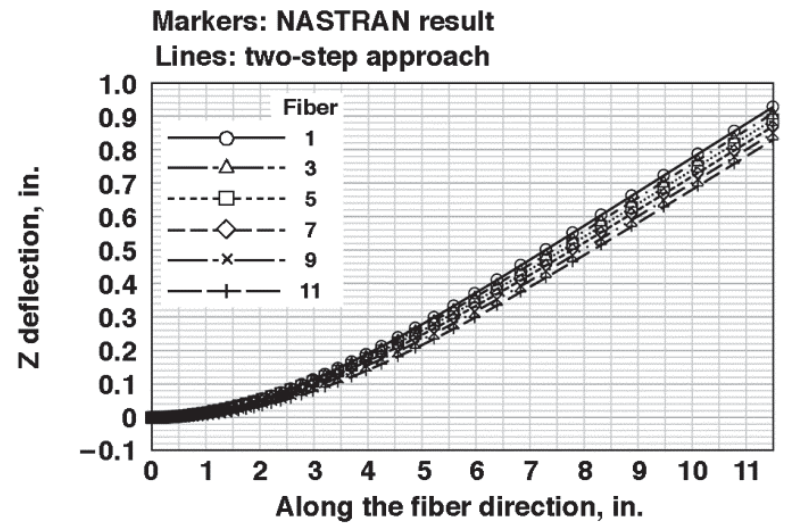

c) $Z$ deflection (step 2 results with 10 modes).

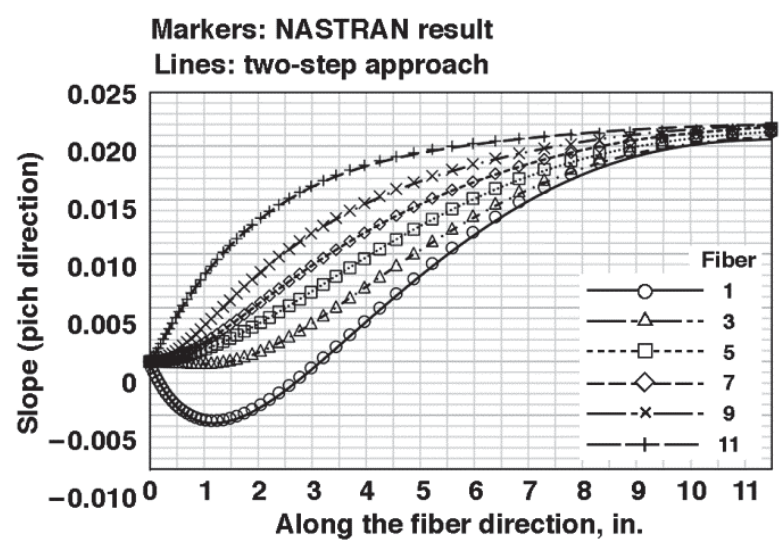

e) Wing slope in pitch direction (step 2 results with 10 modes).

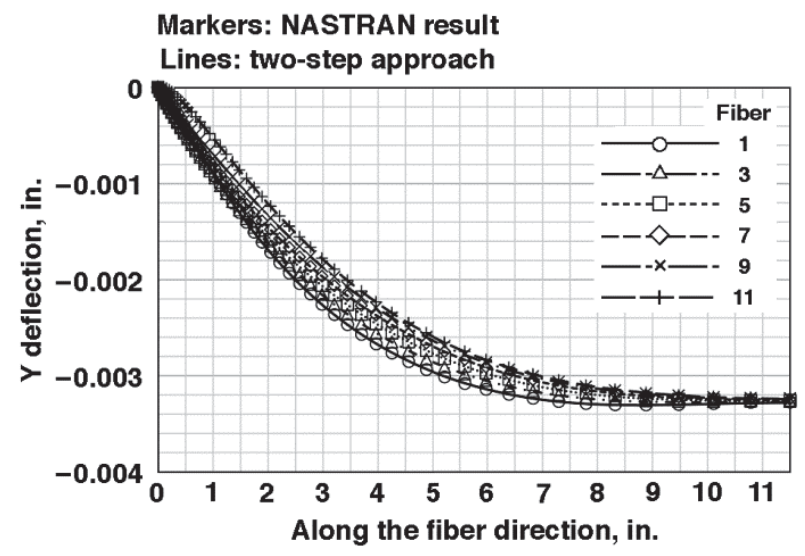

b) Y deflection (step 2 results with 10 modes).

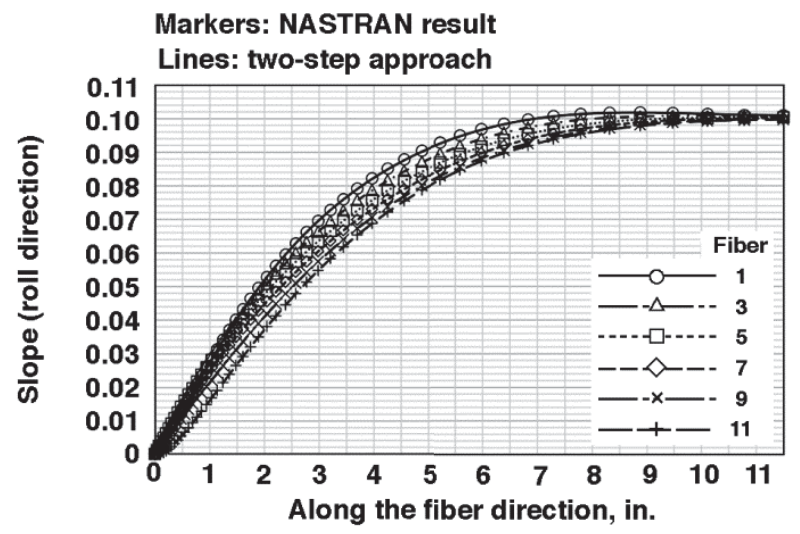

d) Wing slope in roll direction (step 2 results with 10 modes).

Markers: NASTRAN result Lines: two-step approach

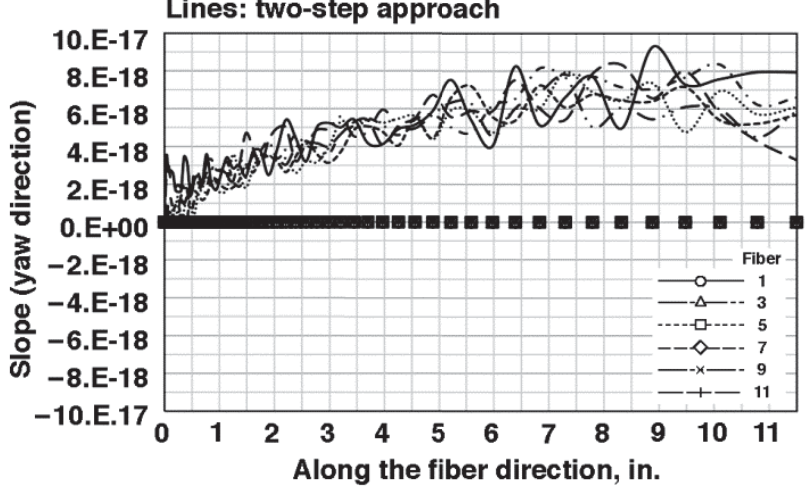

f) Wing slope in yaw direction (step 2 results with 10 modes).

Figure 13. Six DOF wing deformation comparison between MSC/NASTRAN and the two-step approach under $1^{\circ}$ angle of attack at Mach 0.715 . 


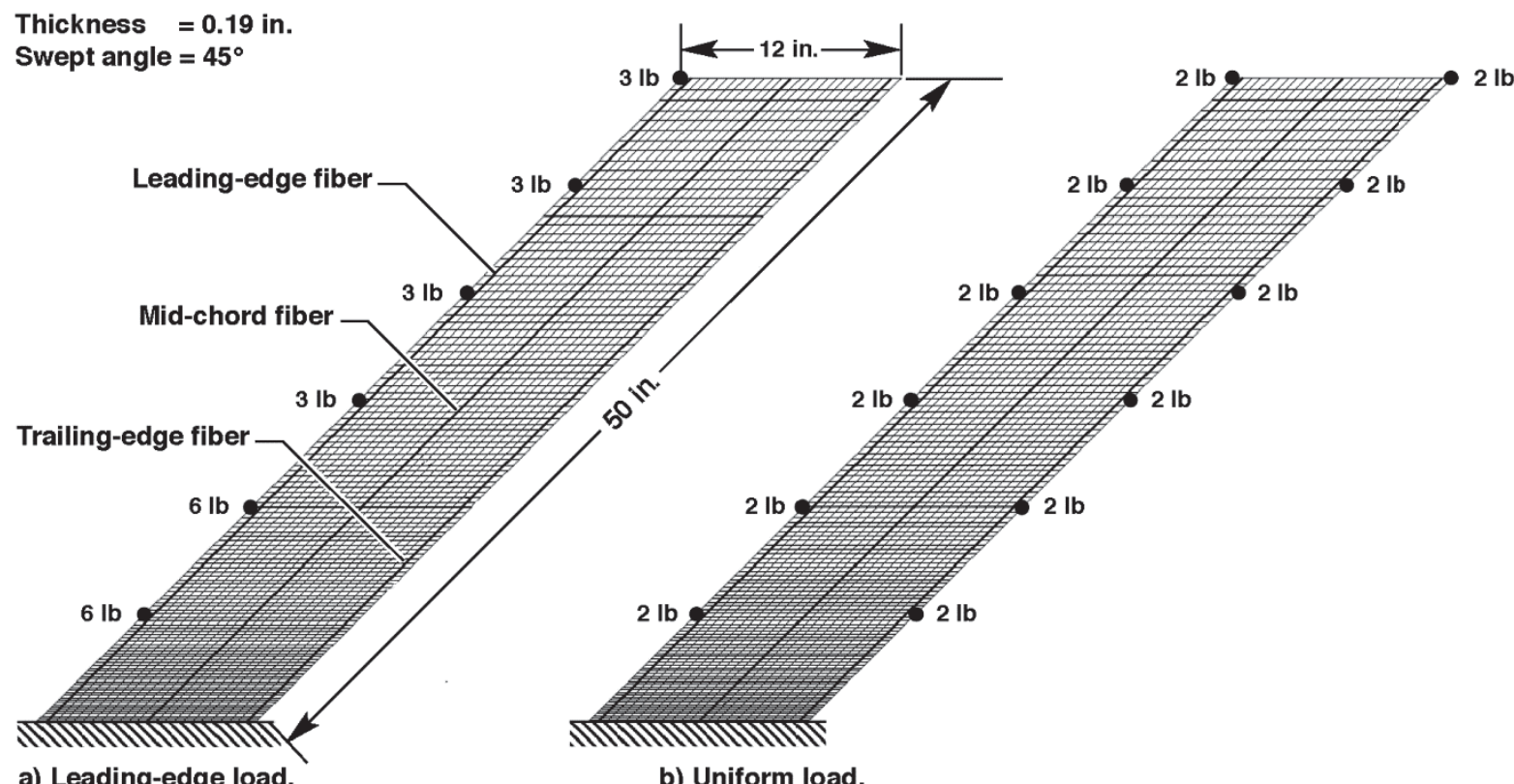

a) Leading-edge load.

b) Uniform load.

Figure 14. FE model with two load cases for the test plate.

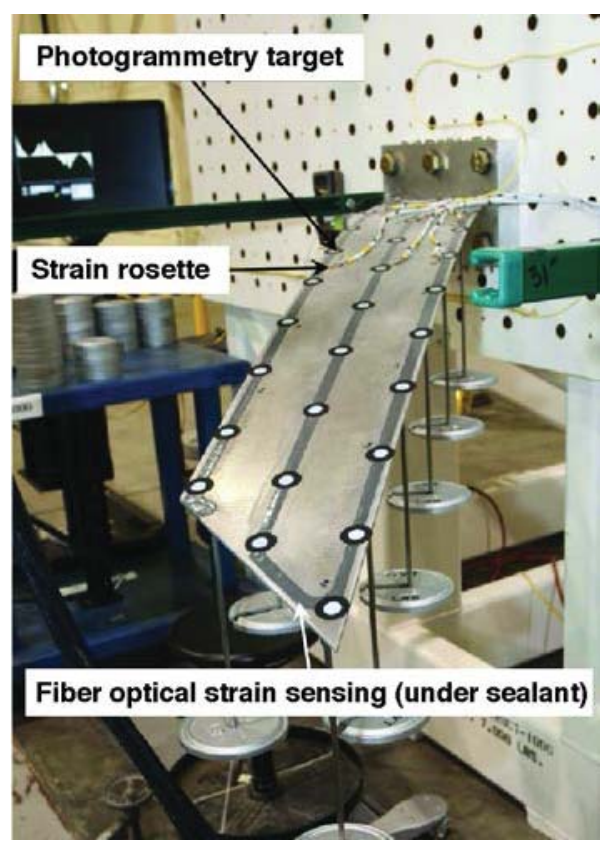

Figure 15. Test setup for the test plate. 


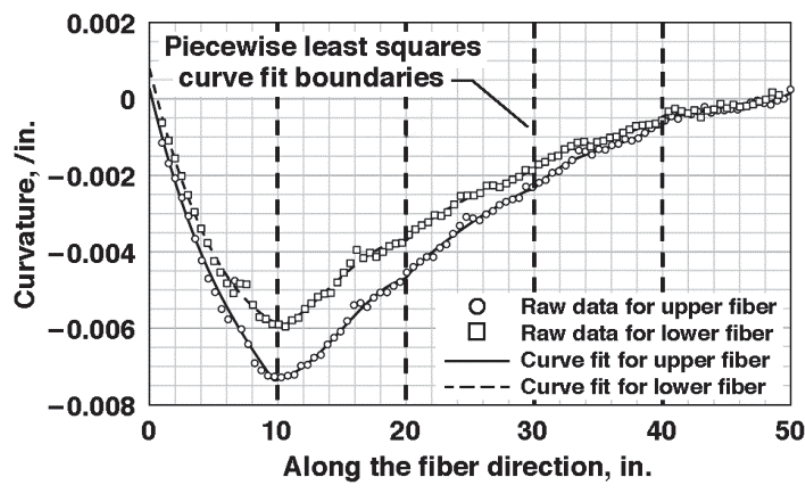

a) Leading-edge load.

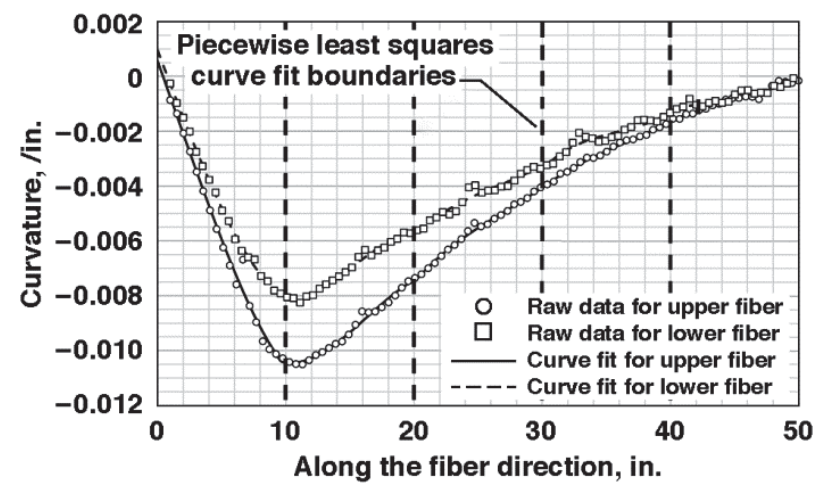

b) Uniform load.

Figure 16. Piecewise least squares curve fit of curvature data along the leading-edge fiber for the test plate. 


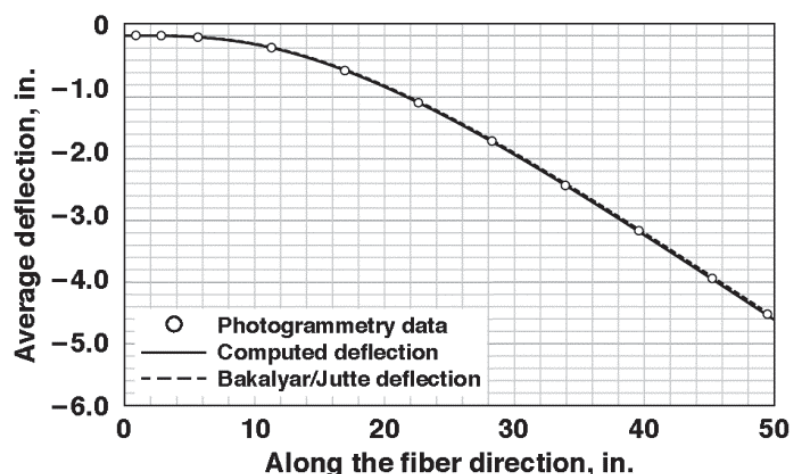

a) Leading-edge fiber (step 1 result).

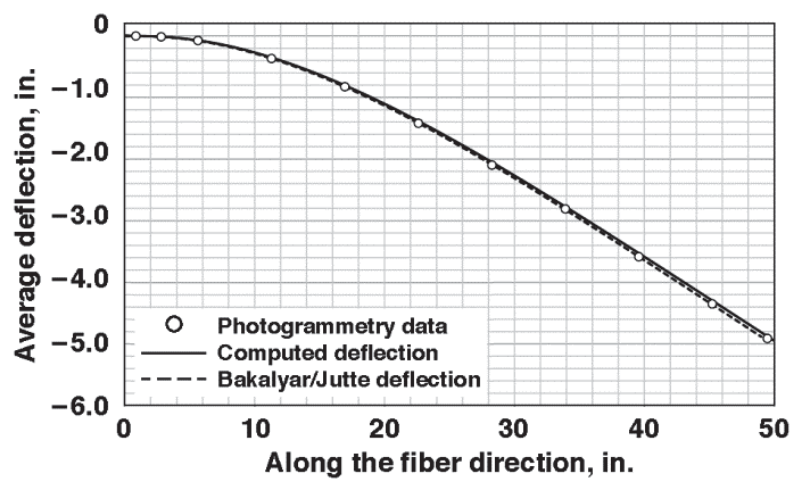

c) Mid-chord fiber (step 1 result).

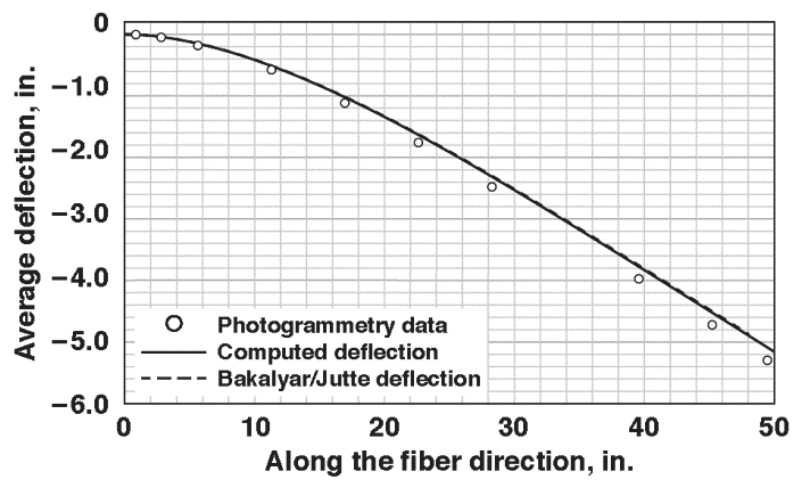

e) Trailing-edge fiber (step 1 result).

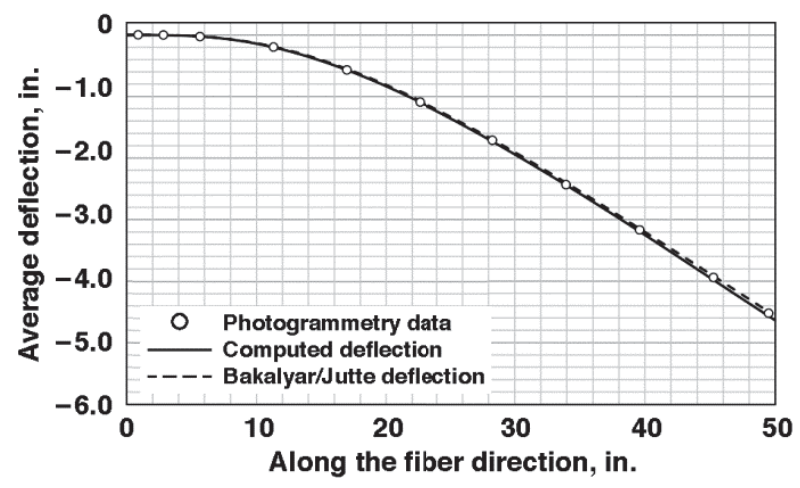

b) Leading-edge fiber (step 2 result with 10 modes).

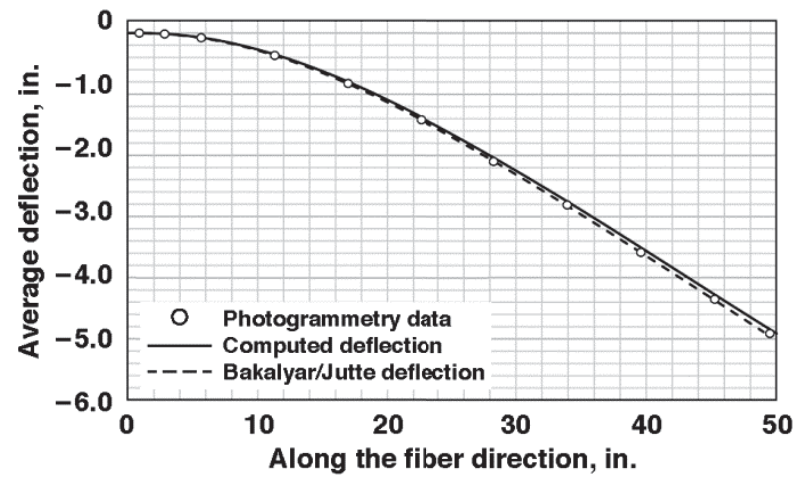

d) Mid-chord fiber (step 2 result with 10 modes).

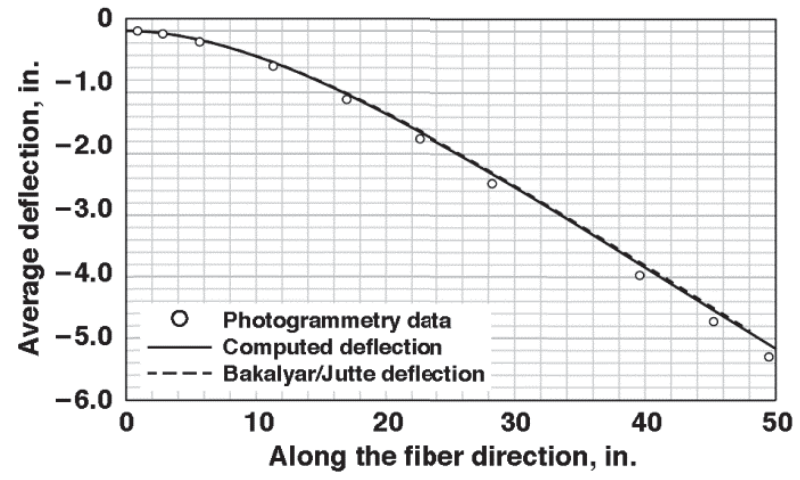

f) Trailing-edge fiber (step 2 result with $\mathbf{1 0}$ modes).

Figure 17. Deflection results under the leading-edge load case for the test plate. 


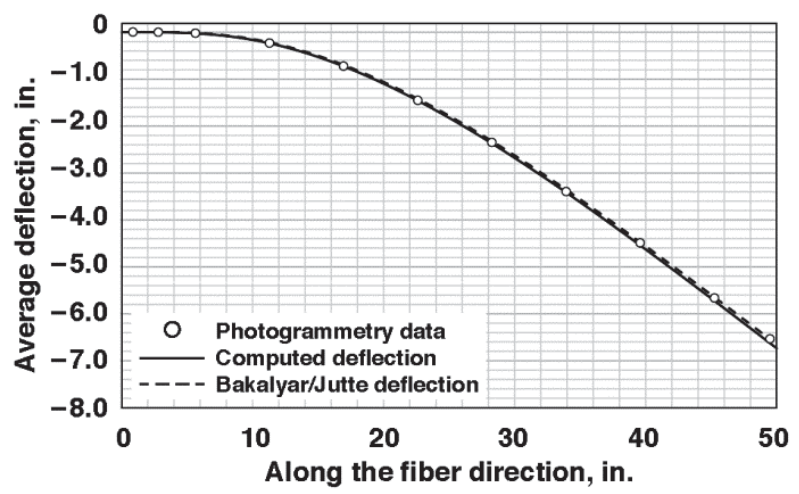

a) Leading-edge fiber (step 1 result).

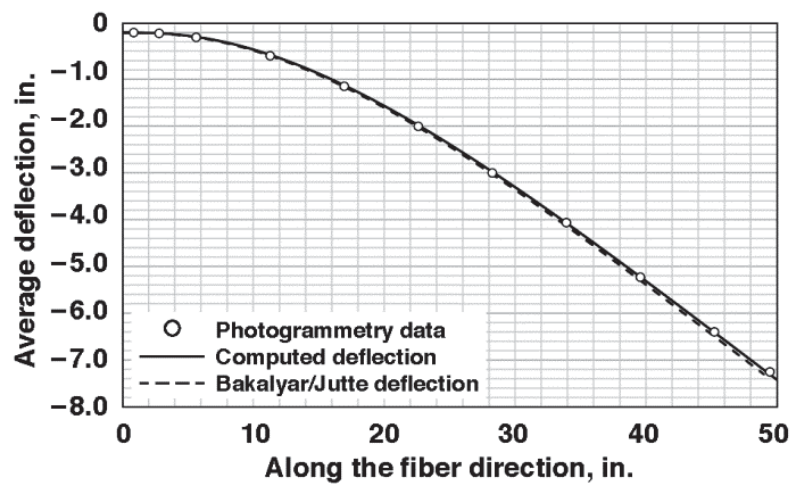

c) Mid-chord fiber (step 1 result).

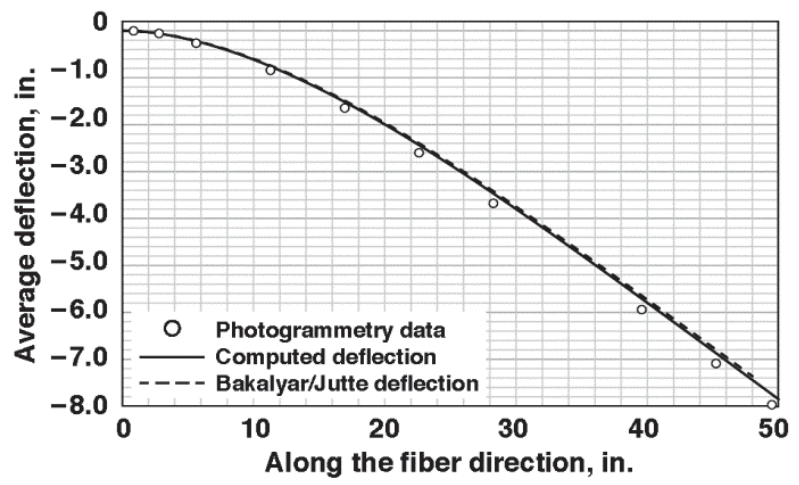

e) Trailing-edge fiber (step 1 result).

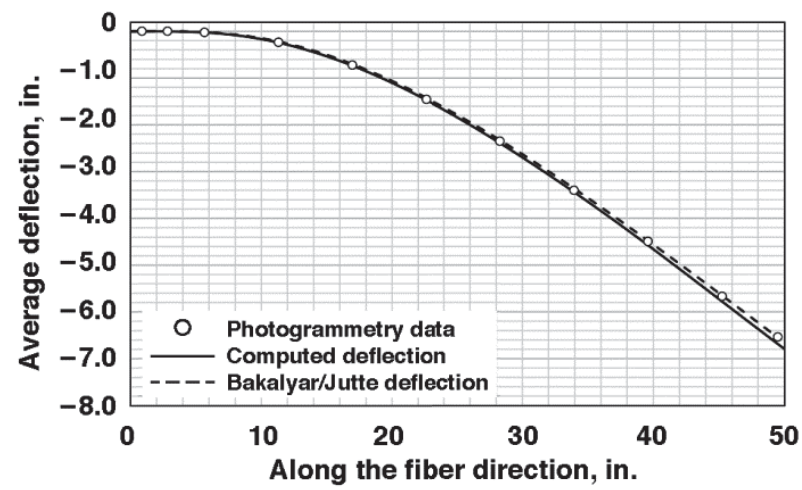

b) Leading-edge fiber (step 2 result with 10 modes).

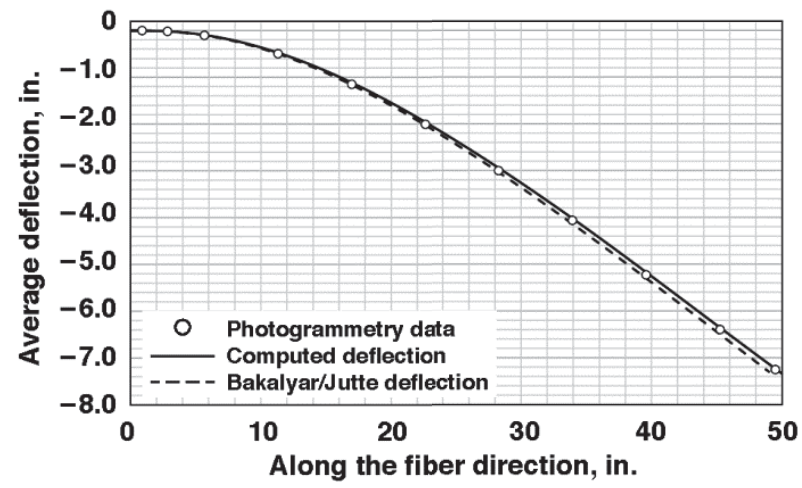

d) Mid-chord fiber (step 2 result with 10 modes).

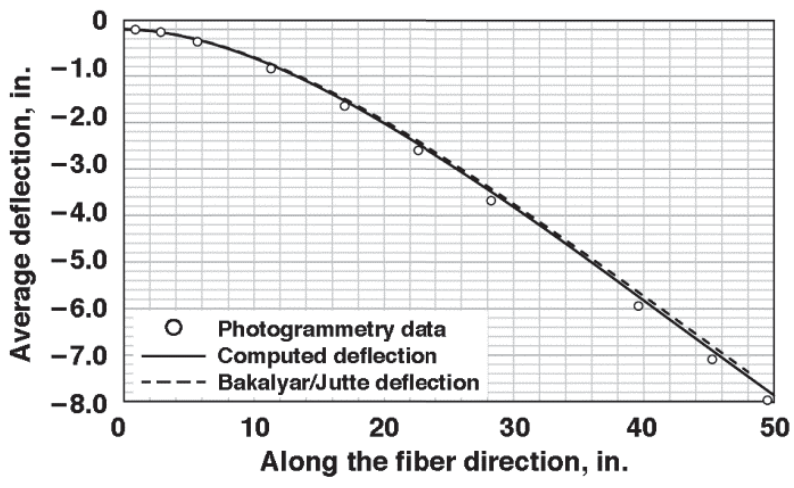

f) Trailing-edge fiber (step 2 result with 10 modes).

Figure 18. Deflection results under a uniform load case for the test plate. 


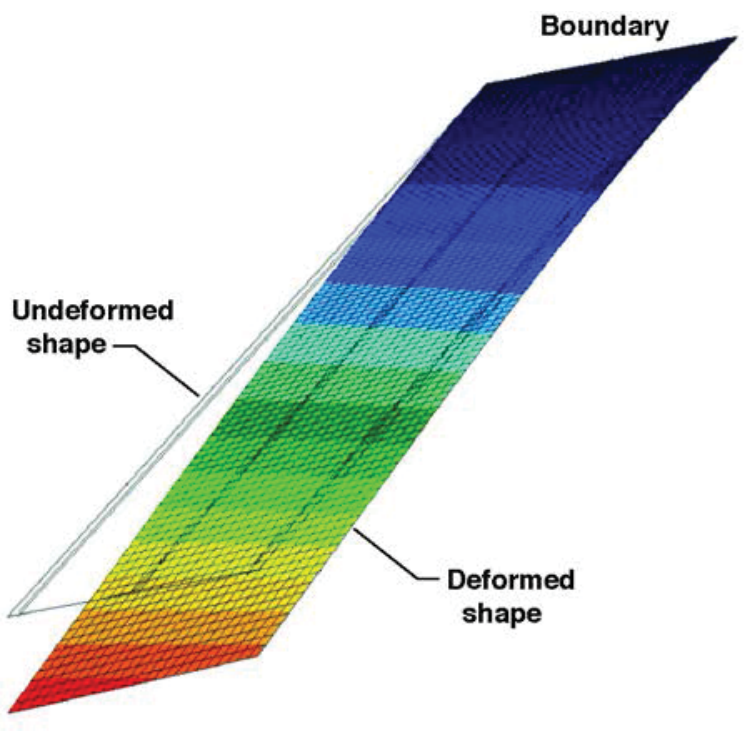

a) Leading-edge load.

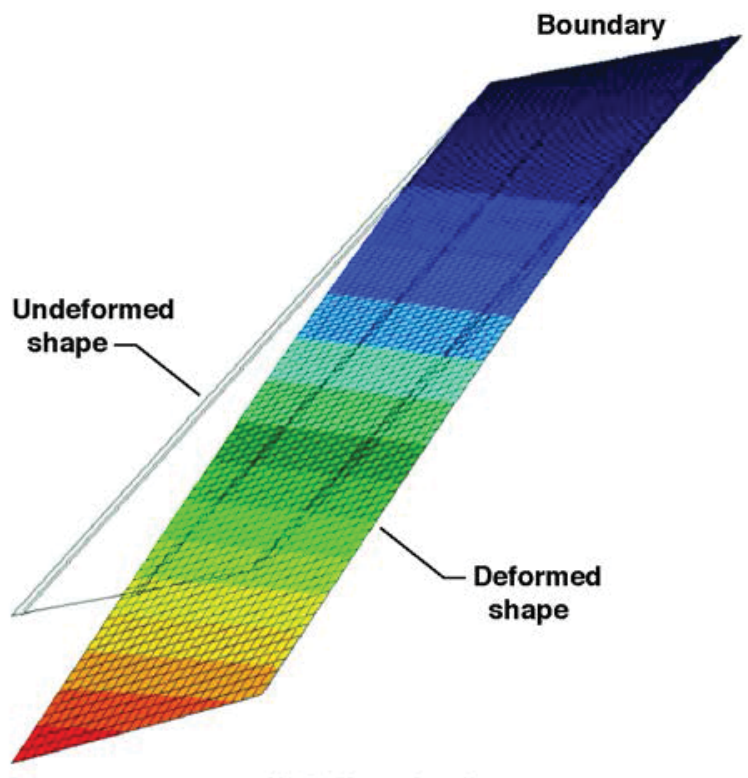

b) Uniform load.

Figure 19. Deformed wing shapes (step 2 results with 10 modes) for the test plate.

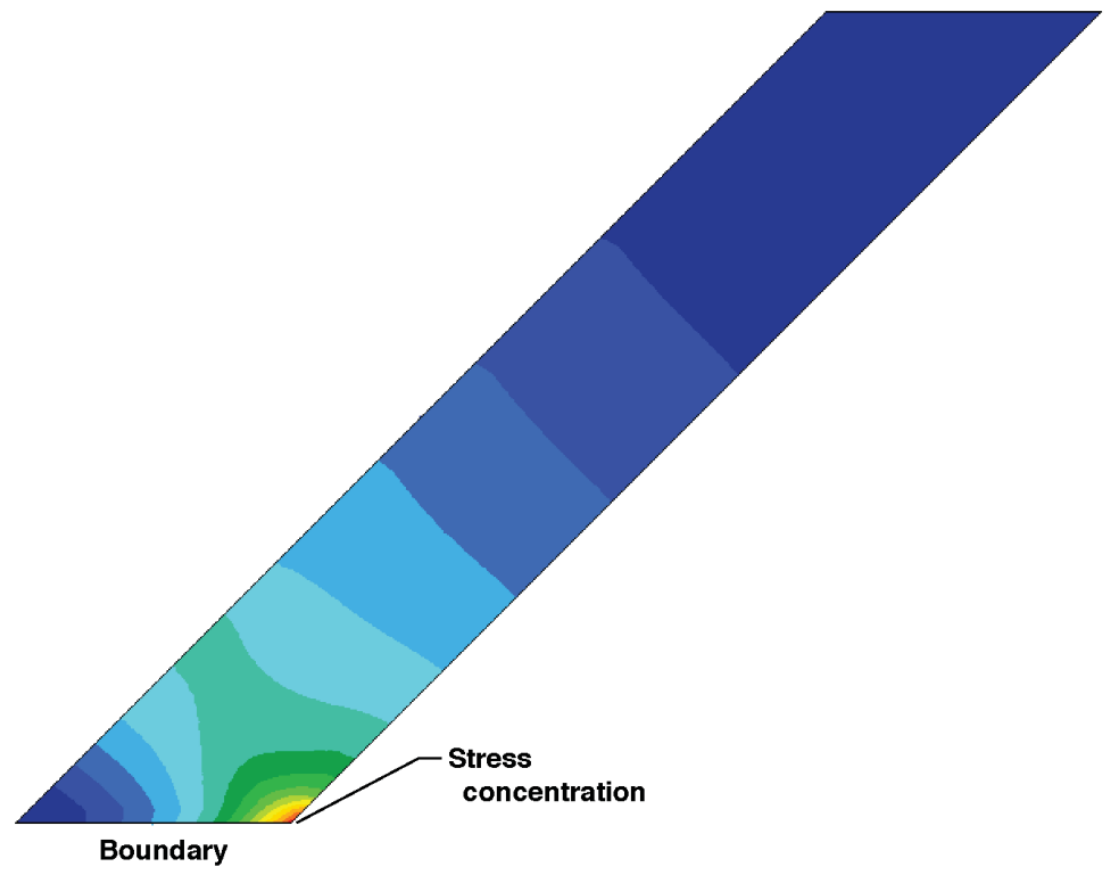

Figure 20. Stress distributions near the root under the leading-edge load case for the test plate. 


\section{References}

${ }^{1}$ Lizotte, A. M., and Lokos, W. A., "Deflection-Based Structural Loads Estimation from the Active Aeroelastic Wing F/A-18 Aircraft,” NASA TM-2005-212871, 2005.

${ }^{2}$ Ko, W. L., Richards, W. L., and Tran, V. T., "Displacement Theories for In-Flight Deformed Shape Predictions of Aerospace Structures,” NASA TP-2007-214612, 2007.

${ }^{3}$ Ko, W. L., and Richards, W. L., “Method for Real-Time Structure Shape-Sensing,” U.S. Patent No. 7,520,176, issued April 21, 2009.

${ }^{4}$ Richards, W. L., and Ko, W. L., "Process for Using Surface Strain Measurements to Obtain Operational Loads for Complex Structures,” U.S. Patent No. 7,715,994, issued May 11, 2010.

${ }^{5}$ Kang, L.-H., Kim, D.-K, and Han, J.-J, "Estimation of Dynamic Structural Displacements Using Fiber Bragg Grating Strain Sensors,” Journal of Sound and Vibration, Vol. 305, No. 3, 2007, pp. 534-542.

${ }^{6}$ Moore, J. P., "Method and Apparatus for Shape and End Position Determination using an Optical Fiber,” U.S. Patent No. 7813599, issued October 12, 2010.

${ }^{7}$ Park, Y.-L., Elayaperumal, S., Daniel, B., Ryu, S. C., Shin, M., Savall, J., and et al., "Real-Time Estimation of ThreeDimensional Needle Shape and Deflection for MRI-Guided Interventions,” IEEE/ASME Transactions on Mechatronics, Vol. 15, No. 6, 2010, pp. 906-915.

${ }^{8}$ Noll, T. E., Brown, J. M., Perez-Davis, M. E., Ishamael, S. D., Tiffany, G. C., and Gaier, M., "Investigation of the Helios Prototype Aircraft Mishap, Volume I Mishap Report,” NASA, 2004.

${ }^{9}$ Cusano, A., Cutolo, A., Nasser, J., Giordano, M., and Calabrò A., "Dynamic Strain Measurements by Fibre Bragg Grating Sensor," Sensors and Actuators A: Physical, Vol. 110, Issues 1-3, 2004, pp. 276-281.

${ }^{10}$ MSC/NASTRAN Quick Reference Guide Version 69, The MacNeal Schwendler Corporation, Newport Beach, California, 1996.

${ }^{11}$ O’Callahan, J., Avitabile, P., and Riemer, R., “System Equivalent Reduction Expansion Process,” Proceedings of the $7^{\text {th }}$ International Modal Analysis Conference, Las Vegas, Nevada, 1989, pp. 29-37.

${ }^{12}$ ZAERO User's Manual Version 8.2, ZONA Technology, Inc., Scottsdale, Arizona, 2008.

${ }^{13}$ Doggett, R.V. Jr., Rainey, A. G., and Morgan, H. G., "An Experimental Investigation of Aerodynamic Effects of Airfoil Thickness on Transonic Flutter Characteristics,” NASA-TMX-79, 1959.

${ }^{14}$ Bakalyar, J. and Jutte C., "Validation Tests of Fiber Optic Strain-Based Operational Shape and Load Measurements," AIAA-2012-2904, 2012. 